\title{
VI. Deutschlandpolitische Implikationen des Instituts 99
}

Im Sommer $1944 \mathrm{kam}$ zu den bisherigen Aufgaben des Instituts 99 eine neue hinzu. In Vorbereitung auf die baldige Besetzung deutschen Territoriums durch die Rote Armee begann unter tatkräftiger Mithilfe der Exil-KPD die Schulung kommunistischer Parteifunktionäre für den Aufbau eines antifaschistischen Nachkriegsdeutschland. Im ZK der VKP (b) entstand die Abteilung „Außenpolitische Information" (otdel meždunarodnoj informacii-OMI), die die Institute 99, 100 und 205 in ihre Verwaltung übernahm. Der Zeitpunkt der Gründung des OMI ist durchaus als Zäsur zu begreifen. Im Volkskommissariat für Äußere Angelegenheiten wurden die Pläne für die zúkünftige Besatzungsverwaltung in Deutschland erarbeitet ${ }^{1}$ und die 7. Verwaltung des GlavPURKKA im August umstrukturiert, um besser auf die Besatzungsaufgaben der Roten Armee vorbereitet zu sein². Der Rat für militärpolitische Propaganda, bis dahin das für die Anleitung des NKFD politisch maßgebliche Gremium (Ščerbakov), wurde im Juli 1944 aufgelöst. Manuil'skij verließ die Politische Hauptverwaltung und trat als Koordinator in der politischen Arbeit unter den Kriegsgefangenen nicht mehr in Erscheinung. Seine Rolle übernahm der ehemalige Generalsekretär der Komintern Dimitrov, der in seiner Eigenschaft als Leiter der neuen ZK-Abteilung zugleich oberster Vorgesetzter des Instituts 99 wurde. Ohnehin war durch das „Büro Dimitrov“ auch nach Auflösung der Komintern das Anleitungsverhältnis zu den exilkommunistischen Parteien immer aufrechterhalten worden ${ }^{3}$. Aber erst mit den institutionellen Änderungen des Sommers 1944 begannen die Mitarbeiter des Instituts 99, sich konkret mit den kommenden Aufgaben sowjetischer Besatzungspolitik in Deutschland zu beschäftigen.

\section{Parteischulungen}

Die Vorbereitungen auf die durch den bevorstehenden Einmarsch der Roten Armee nach Deutschland zu erwartenden Besatzungsaufgaben begannen im Juli 1944. Zu der turnusgemäßen Zivilsektorsitzung am 10. Juli 1944 kamen die maßgeblichen Vertreter der 7. Verwaltung (Burcev, Braginskij) und der operativen Abteilung des UPVI (Švec) hinzu. Auf dieser Sitzung wurde über organisatorische Schritte gesprochen, obwohl die politischen Beschlüsse, auf deren Grundlage das Institut 99

Siehe die entsprechenden Dokumente, in: SSSR i germanskij vopros, tom I, S. $489 \mathrm{ff}$.

2 Vsevolodov, Vzaimodejstvic politorganov, Anlage Nr. 3; vgl. Burzew, Einsichten, S. 236.

3 Adibekov, Kominform, S. 14; SSSR - Polša, S. 7; Foitzik, Zur Anleitung der kommunistischen Parteien, S. 509 ff.; vgl. den Bestand „Büro Dimitrov“ im RGASPI fond 495 opisi 73-77, Kratkij putevoditel', S. 82. 
hätte aktiv werden können, noch fehlten. Gerö wurde daher beauftragt, politische Instruktionen einzuholen, „um nächste Sitzung konkrete Maßnahmen zu beschließen" 4 . Bereits am 10. Juli wurde eine Kommission (Kozlov, Braginskij und Ackermann) zur Aktualisierung der Schulungsprogramme an den Antifa-Schulen eingesetzt. Vermutlich sollte die Ausbildung an den Schulen besser auf die zu erwartenden Bedürfnisse der Roten Armee bei der Bewältigung von Besatzungsaufgaben in Deutschland abgestimmt werden, denn es wurde noch eine zweite Kommission gebildet (Ulbricht, Försterling, Bredel, Köppe, Wolf, Noffke), die eine Auswahl von 200 Absolventen der Antifa-Schulen „für die bevorstehenden Aufgaben" treffen sollte ${ }^{5}$.

Über die Beratungen im Institut 99 gibt auch der Brief Wilhelm Piecks an Dimitrov vom 13. Juli 1944 Aufschluß. Pieck schlug darin vor, daß noch vor dem Einmarsch der Roten Armee ausgewählte Kriegsgefangene in den Kreisstädten („Hauptstadt des Bezirks“) den Aufbau von Untergrundorganisationen in die Wege leiten („Schaffung von Vertrauensleuten“), Sabotageakte durchführen („Verhinderung der Kriegsproduktion“) und allgemein Parolen für den Sturz Hitlers verbreiten sollten. In Übereinstimmung mit den Beschlüssen des Instituts 99, Auswahl und Zusammenstellung der Antifa-Kader "bezirksweise“ vorzunehmen, machte Pieck konkrete quantitative und qualitative Vorgaben. Allgemein solle auf die Rekrutierung von Spezialisten („Wirtschaftler, Lehrer und dergleichen“) geachtet werden. Als „Kader für politisch besonders verantwortliche Aufgaben nach der Besetzung“ seien je 25 Kriegsgefangene als Zeitungs- bzw. Radioredakteure und 30 Kriegsgefangene als Schulungsleiter sowie Mitarbeiter zur Einrichtung eines zentralen Pressedienstes auszubilden. Für den Einsatz in staatlichen Verwaltungen und Massenorganisationen - Pieck nannte Gewerkschaften, Bauernbund und Jugendorganisationen - seien Antifa-Schüler zu verwenden, „die mit dem betreffenden Bezirk verbunden sind, die politisch zuverlässig sind, die Spezialkenntnisse haben. Wir schlagen vor, daß zu diesem Zweck je nach der Größe des Bezirks im Durchschnitt 200 Mann je Bezirk ausgewählt werden." ${ }^{6}$ Als weiteren Punkt sprach Pieck die „Vorbereitung der ideologischen Umerziehung des deutschen Volkes" und die Zusammenstellung von Informations- und Aufklärungsmaterial für diese Zwecke an. Mit der Ausarbeitung von Materialien sei bereits begonnen worden, womit Pieck einerseits die Ergebnisse der Arbeitskommission der KPD, andererseits die Aktivitäten des Instituts 99 in der sogenannten Broschürenkommission gemeint haben könnte ${ }^{7}$.

Pieck stützte sich in seinem Brief auf Beschlüsse des Instituts 99, ohne dies explizit zu erwähnen. Seine detaillierten Vorschläge gingen unmittelbar auf die Ergebnisse der Zivilsektorsitzung des Instituts 99 vom 10 . Juli zurück, wurden aber als zu beratende "Probleme“ dargestellt, mit denen sich die KPD an das ZK der VKP (b) wandte. Es ist nicht ausgeschlossen, daß die KPD auf diese Weise versuchte, nicht nur im Institut 99, sondern auch im OMI an den Absprachen beteiligt zu werden.

4 Beschlußprotokoll des Instituts 99 vom 10. 7. 1944, RGASPI 495/77/46, Bl. 4, erster Tagesordnungspunkt „politische und propagandistische Aufgaben der nächsten Zukunft".

5 Ebenda, zweiter Tagesordnungspunkt: „Frage der Beschaffung und Verwendung von Kadern für die bevorstehenden Aufgaben".

6 Pieck an Dimitrov am 13. 7. 1944, in: „Gruppe Ulbricht“, S. $110 \mathrm{f}$.

7 Ebenda, S. 111; zur Broschürenkommission siehe unten S. $150 \mathrm{f}$. 
Wahrscheinlicher ist es jedoch, daß in alter Kominterntradition die KPD als scheinbar eigenständig agierende Partei auftreten sollte, während die Entscheidungen im ZK der VKP (b) fielen und mit dessen Apparat, dem Institut 99, umgesetzt wurden. Nicht ohne Grund hatte Pieck über den fehlenden Einfluß der KPD auf Kaderentscheidungen geklagt: „Seit Bestehen des Nationalkomitees werden alle Kaderfragen der Kriegsgefangenenschulen ausschließlich von Genossen der NKWD erledigt. Wir haben bisher weder Kenntnis über die Charakteristiken, noch konnten wir an der Arbeit teilnehmen, und auch die Schulungsprogramme der letzten zwei Schulen [Antifa-Kurse] wurden ohne unsere Kenntnis ausgearbeitet." 8 Es bleibt kein Zweifel daran, daß OMI und Institut 99 die organisatorisch entscheidenden Instanzen waren und es auch im weiteren blieben.

Die Vorschläge des Instituts 99 respektive Piecks blieben einige Wochen liegen, da durch das Attentat auf Hitler vom 20. Juli und den Beitritt von Generalfeldmarschall Paulus die Propaganda des NKFD stark im Vordergrund stand. Aber am 7. August kam der Zivilsektor im Institut 99 auf seine Vorschläge zurück und drängte auf eine Klärung: „Es wird beschlossen, die Genossen Pieck und Gerö zu beauftragen, sich mit den zuständigen Organen in Verbindung zu setzen, um durch diese eine Unterstützung bei der Realisierung der in Angriff zu nehmenden Arbeit zu erwirken. "9 Am Tag darauf erinnerte Pieck Dimitrov an seine Vorschläge vom 13. Juli: „Ich äußerte schon vor einiger Zeit in einem Briefe den Wunsch, daß Du mich, Ulbricht und Ackermann zu einer Besprechung über die Kaderfragen für Deutschland einladen solltest."10 Am 9. August wurden die Vertreter der KPD (Pieck, Ulbricht, Ackermann) zu Dimitrov in das OMI gebeten. Im Mittelpunkt der Gespräche standen - wie Pieck notierte - „Kaderfragen für das Land“. Es wurde die Frage der in der Emigration verstreuten und in Deutschland befindlichen KPDMitglieder erörtert („Wo sind die kommunistischen Kader?"). In diesem Zusammenhang wurde das Problem der Exil-KPD angesprochen, daß sie zu den Parteimitglieder in Deutschland keine Verbindung hatte: „... im Lande $=8000-10000$, die ohne Verbindung und verwendungsfähig in Gebieten“. Ähnliche Schwierigkeiten galten für die im sowjetischen Exil lebenden KPD-Mitglieder. Sie waren weit über die Republiken der Sowjetunion verstreut ${ }^{11}$, so daß sie für einen zentral von Moskau aus gesteuerten Einsatz als Parteikader, dem ohnehin eine Prüfung vorausgehen mußte, nicht unmittelbar zur Verfügung standen („Kaderfrage, herholen von Gebieten zur Prüfung, ob geeignet“). Als ersten, organisatorisch machbaren Schritt trug Dimitrov der KPD daher auf, eine Liste „von Genossen, die sehr bald ins Land [Deutschland] geschickt werden, nach Gebieten und Funktionen" aufzustellen ${ }^{12}$. Diese von der KPD in den folgenden Wochen erstellte Auflistung wurde dann allerdings erst am 28. November 1944 im OMI beraten ${ }^{13}$. Einziger unmittelbarer Kader-

8 Pieck an Dimitrov am 13. 7. 1944, in: „Gruppe Ulbricht“, S. 110.

9 Beschlußprotokoll des Instituts 99 vom 7. 8. 1944, RGASPI 495/77/46, Bl. 10.

10 Pieck an Dimitrov am 8. 8. 1944, in: „Gruppe Ulbricht“, S. 125.

$11 \mathrm{Zu} \mathrm{dem}$ wechselhaften Schicksal deutscher Emigranten in der Sowjetunion siehe Tischler, Flucht in die Verfolgung, insbes. S. $150 \mathrm{ff}$. und $176 \mathrm{ff}$.

12 „Kaderfragen für das Land, Bericht Ulbricht, Briefe vom 12. 7. + 8. 8.“, Notizen Piecks vom 9. 8. 1944, in: „Gruppe Ulbricht“, S. 118. Pieck meinte ganz offensichtlich den Brief vom 13. 7. 1944, vgl. ebenda, Anm. 2.

13 „Vorschläge zur Vorbereitung leitender Kader“ und handschriftlicher Vermerk am unteren 
einsatz nach der Besprechung im OMI am 9. August war die Einschleusung von fünf Kommunisten nach Deutschland, die im Institut 100 auf derartige Einsätze vorbereitet worden waren. Sie sollten Kontakt mit im Untergrund befindlichen Parteifunktionären aufnehmen. Die Einsätze scheiterten jedoch und blieben somit für die weitere Planung des OMI ohne Auswirkung ${ }^{14}$.

Im Mittelpunkt der deutschlandpolitischen Planungen des OMI stand im Herbst 1944 die Rekrutierung neuer Kader unter Einbeziehung von Kriegsgefangenen. Allerdings sollte nicht - wie vom Institut 99 vorgeschlagen - die Ausbildung für den Einsatz in Deutschland in die Antifa-Schulung integriert werden. Dimitrov ordnete statt dessen an, kommunistische Emigranten zusammen mit vertrauenswürdigen Kriegsgefangenen in separat durchgeführten Parteischulungen vorzubereiten. Als „Ausführung der Beschlüsse vom 9. 8. 1944“ notierte sich Pieck: „Aufstellung einer Liste von Genossen, die für die Parteischule (bei Moskau) in Frage kommen. Vorbereitung für das Land. Zusammen mit kriegsgefangenen Kommunisten aus verschiedenen sozialen Schichten und Berufen. Lehrplan ausarbeiten - Abendkurse in Moskau - Lehrer auswählen - Lehrprogramm." 15 Damit reaktivierte das OMI die mit Auflösung der Komintern eingestellte Schulung ausländischer Parteifunktionäre auf sowjetischem Boden. Vom Frühjahr 1941 bis Juni 1943 waren teils militärisch (in Puškino), teils als Parteischulung (in Kušnarenkovo) ausländische Kommunisten entsprechend ausgebildet worden, um in ihren Heimatländern den Untergrundkampf gegen die faschistischen Regime fortzuführen ${ }^{16}$. Die deutschen Kommunisten waren aber nur zu einem sehr geringen Teil eingesetzt worden. Viele von ihnen wurden nach Auflösung der Komintern vom Institut 100 übernommen und überwiegend erst 1944 mit dem Fallschirm auf deutschem Reichsgebiet abgesetzt. Einige der Kominternschüler, wie Heinz Hoffmann und Gottlieb Grünberg, wurden Politinstrukteure in Kriegsgefangenenlagern oder Lehrer an Antifa-Schulen. Erst mit der Entscheidung des OMI vom 9. August 1944 wurden diese Kominternkader wieder für den Einsatz in Deutschland eingeplant. Im Unterschied zur Kominternschulung wurden nun auch kommunistisch eingestellte Kriegsgefangene („,kriegsgefangene Kommunisten") einbezogen ${ }^{17}$.

Die Parteischulung deutscher Kommunisten und Kriegsgefangener begann am 20. September 1944 in Schodna, ca. 20 Kilometer nordwestlich von Moskau unter der Tarnbezeichnung „Schule Nr. 12“. Wilhelm Pieck nannte sie auch „Schule für

Blattrand der letzten Seite „Die Angelegenheit wird auf der Sitzung bei Genosse Dimitrov am 28. 11. 44 besprochen", RGASPI 495/74/161, Bl. 146-148.

14 Ferdinand Greiner, Artur Hoffmann, Joseph Gieffer, Josef Kiefel und Rudolf Gyptner wurden am 23. 8. 1944 mit dem Fallschirm in der Nähe von Lublin abgesetzt. Gyptner und Gieffer fielen bei dem erfolglosen Unternehmen; Hoffmann, Als Partisan des Nationalkomitees, S. $360 \mathrm{ff} . ;$ Otten, Memento einer Nacht, S. 365 ff.; vgl. Anm. 15 und 16 in: „Gruppe Ulbricht", S. 124.

15 Notizen Piecks „Ausführung der Beschlüsse vom 9. 8. 1944“, in: „Gruppe Ulbricht“, S. 121.

16 Vgl. Leonhard, Revolution, S. $186 \mathrm{ff}$.; allgemein siehe Herlemann, Der deutschsprachige Bereich der Kaderschulen der Kommunistischen Internationale, S. 205 ff.; Morré, Die Parteischulung der KPD in der Sowjetunion.

17 Die KPD hatte das bereits nach den ersten Erfolgen der Antifa-Schulung vorgeschlagen, das war aber von Dimitrov abgelehnt worden; siehe oben, S 125. 
das Land"18. Den Organisationsplan hatte die KPD nach den Anweisungen Dimitrovs entworfen: In einem sechswöchigen Kurs sollten 40 bis 50 Funlstionäre geschult werden. Zuerst sollten die in Moskau und Umgebung befindlichen, dann die in den sowjetischen Republiken lebenden KPD-Mitglieder und Kriegsgefangenen die Schule besuchen. Als Lehrer waren Hermann Matern (zugleich sogenannter Sektorleiter), Willi Kropp und Gottfried Grünberg vorgesehen. Tatsächlich übernahmen diese Funktionen - für den ersten Kurs - Kropp und Fred Oelßner ${ }^{19}$. Der Beschluß zur Errichtung der Schule Nr. 12 legte die organisatorischen Formen dann so fest, daß eine vollständige Kontrolle durch das OMI gewährleistet war. Zum Schulleiter wurde der OMI-Funktionär Konstantin Vilkov ernannt ${ }^{20}$. Die Ausstattung der Schule oblag ebenfalls dem OMI (Baranov) und die Finanzierung erfolgte durch die Geschäftsabteilung des ZK der VKP (b) (Sucharev). Die Schulungsdauer wurde, wie von der KPD vorgeschlagen, auf sechs Wochen, beginnend am 20. September 1944, festgesetzt. Die Zahl der Schüler aber wurde auf 35 Personen pro Lehrgang begrenzt. Schulungsziel war die Ausbildung von „Parteikadern der mittleren Führungsschicht der KP Deutschlands“. Verantwortlich für die Auswahl der Schüler und der Lehrer sowie die Gestaltung des Programms war das Institut 99 (Kozlov) ${ }^{21}$.

Die Auswahl der Parteischüler begann am 7. September unter der Leitung Kozlovs zusammen mit dem Schulleiter Vilkov, einem Mitarbeiter der Kaderabteilung des OMI (Mirov) und zwei Vertretern der KPD (Ulbricht, Försterling). Zuerst wurden die Mitglieder der KPD ausgewählt. Am 20. September folgte die Nominierung der Kriegsgefangenen ${ }^{22}$. Diese waren in der Regel Absolventen der AntifaSchule oder hatten sich in den Lager-Aktivs hervorgetan. Sie waren zumeist Mitglieder der KPD bzw. des KJVD. Allerdings wichen in den ersten beiden Kursen Nominierung und tatsächliche Aufnahme in die Parteischule erheblich voneinander ab. Viele der nominierten Schüler nahmen erst am zweiten oder gar dritten Kurs teil. Insbesondere bei den Emigranten bestand das Hauptproblem darin, sie aus den fern ab von Moskau gelegenen Landesteilen herbeizuholen, wobei sich worauf noch einzugehen sein wird - das Institut 99 als nicht sonderlich kooperativ gegenüber der KPD zeigte. In allen Kursen der Parteischule wurden immer mehr Kriegsgefangene als Zivilisten geschult ${ }^{23}$.

Das Schulungsprogramm ging auf einen Entwurf der KPD zurück. Es baute auf den Vorkenntnissen aus den Antifa-Schulen auf und verstand sich als deren Anpas-

$18 \mathrm{Vgl}$. Tischler, Flucht in die Verfolgung, S. $217 \mathrm{ff}$.; Hoffmann, Moskau Berlin, S. $111 \mathrm{ff} . ;$ Grünberg, Kumpel, Kämpfer, Kommunist, S. 207; Dengler, Zwei Leben in einem, S. $133 \mathrm{f}$.

19 „Entwurf eines Organisationsplanes der Parteischule“ als Anlage zu dem Brief Piecks an Dimitrov am 15. 8. 1944, RGASPI 495/74/161, Bl. 12-13 (=SAPMO-BArch NY 4036/544, Bl. 47 und NY 4036/530, Bl. 2); vgl. Protokoll der Aufnahmekommission der Schule Nr. 12 vom 7. 9. 1944, ebenda, Bl. 52.

20 Vilkov war seit Herbst 1939 stellvertretender Leiter der Kaderabteilung der Komintern und gehörte auch nach Auflösung der Komintern zum engsten Mitarbeiterstab Dimitrovs; Huber, Stalins Schatten in die Schweiz, S. 458.

21 Beschlußvorlage für das OMI als Anlage zum Brief Vilkovs an Mirov (Sekretatriat des OMI) vom 8. 9. 1944, RGASPI 495/74/161, Bl. 43-44.

22 „Protokoll Nr. 1“ vom 7.9. 1944 und "Protokoll Nr. 2“ vom 20.9. 1944, RGASPI 495/74/161, Bl. 52-53 RS und Bl. 69-72.

23 Siehe Anlage Nr. 2. 
sung an die aktuellen Gegebenheiten ${ }^{24}$. $\mathrm{Zu}$ einem großen Teil war es jedoch eine Wiederholung dessen, was auch auf den Antifa-Schulen vermittelt wurde. In fünf ungefähr gleich großen Themenblöcken von 40-45 Unterrichtsstunden wurde eine Einführung in den Marxismus-Leninismus, eine Auseinandersetzung mit dem Nationalsozialismus („Widerlegung der faschistischen Theorie“), die Geschichte der Arbeiterbewegung bis 1933, die Geschichte der Arbeiterbewegung nach 1933 sowie die Geschichte der Sowjetunion vermittelt. Lediglich der sechste Unterrichtsblock - mit 79 Stunden doppelt so umfangreich wie die vorhergehenden Themeneinheiten - ging über das Antifa-Programm hinaus. Hier wurde konkret das Vorgehen in Deutschland nach dem Krieg dargelegt. Dieser Teil des Programms stützte sich auf die Ausarbeitungen der KPD-Arbeitskommission, deren Referenten über die Entnazifizierung (Johannes R. Becher), die Wirtschaft (Anton Ackermann), die Landwirtschaft (Edwin Hoernle), die Jugendorganisationen (Hans Mahle), die Gewerkschaften (Hermann Matern), die Genossenschaften (Otto Winzer) und das Vorgehen beim Aufbau der KPD (Wilhelm Pieck) sowie die Einbeziehung der Sozialdemokraten im Sinne der „Einheit der Arbeiterklasse“ (Walter Ulbricht) sprachen $^{25}$.

Der sechswöchigen theoretischen Schulung in Schodna folgte eine praktische Ausbildung in der technischen Schule des Instituts 10026. Die dort vermittelte „Parteitechnik" sollte die Absolventen befähigen, Parteizellen im Untergrund aufzubauen und mit Hilfe einfacher Drucktechniken Flugblätter herzustellen. Außerdem gab es eine Einweisung in Waffenkunde ${ }^{27}$. In der Sprache der KPD diente die Zusatzausbildung als Vorbereitung auf den ,illegalen Einsatz“, d.h. für den Einsatz in dem noch nicht von der Roten Armee besetzten Gebiet des Deutschen Reiches. Analog zu den zukünftigen Einsatzgebieten wurden die Schüler auf Seminargruppen verteilt. Dafür waren die Gebiete Berlin, Hamburg, Rhein/Ruhr, Sachsen, Baden/Pfalz und Bayern vorgesehen. Da es sich um einen „illegalen Einsatz“ handeln würde, bekamen die Schüler - ebenso wie seinerzeit an der Komintern-Schule Decknamen ${ }^{28}$.

24 „Die grundsätzlichen Fragen des Marxismus-Leninismus wie Partei, Strategie und Taktik, Nationale Frage, Bauernfrage, Staat und andere sollen immer in Verbindung mit den entsprechenden aktuellen Themen behandelt werden.", „Themenplan für die Parteischule“, RGASPI 495/74/161, Bl. 14.

25 Themenplan der Schule Nr. 12, deutsche und russische Variante, beide ohne Datum, SAPMO-BArch NY 4036/530, Bl. 20-23 und RGASPI 495/74/161, Bl. 54-56; vgl. Abschlußbericht des 1. Kurses (Vilkov) vom 29. 1. 1945, RGASPI 17/128/837, Bl. 37-38; zu den Referaten in der Arbeitskommission der KPD siehe „Nach Hitler kommen wir“, S. $161 \mathrm{ff}$.

26 Vilkov an Dimitrov am 27. 10. 1944, RGASPI 495/74/157, Bl. 213; vgl. Pieck an Dimitrov am 18. 11. 1944, RGASPI 495/74/162, Bl. 83 (= SAPMO-BArch NY 4036/544, Bl. 83).

27 Themenplan für die Schule Nr. 12, SAPMO-BArch NY 4036/530, Bl. 20-23; russische Variante mit leicht abweichenden Stundenzahlen, RGASPI 495/74/161, B1. 54-56; vgl. Vorlage vom 15. 8. 1944, ebenda Bl. 14-17 (= SAPMO-BArch NY 4036/530, Bl. 4-7); vgl. Vilkovs Abschlußbericht über den 1. Kurs vom 29. 1. 1945, RGASPI 17/128/837, Bl. 33-36.

28 Aufstellung Vilkovs vom 23. 10. 1944, RGVA/K 88/2/2, Bl. 235. Pieck notierte sich die regionale Aufteilung ein wenig anders, vor allem ging er - wofür es in den russischen Dokumenten keinen Beleg gibt - auch von einer schlesischen Gruppe aus. Nach dem Pieck-Notat waren es die Gebiete Berlin, Wasserkante, Sachsen, Schlesien, Rheinland-Westfalen und Bayern/Baden/Hessen, SAPMO-BArch NY 4036/530, Bl. 18. 
Der erste Kurs an der Schule Nr. 12 endete am 15. November 1944. Pieck kümmerte sich um den Einsatz der Absolventen. Bereits am 1. November schickte er an Dimitrov eine Liste mit Namen und Einsatzgebieten der Parteikader. Außerdem bemühte er sich um die Beschaffung von deutschen Formularen und Stempeln, um Falschpapiere anfertigen zu können, mit denen die Absolventen nach Deutschland eingeschleust werden könnten ${ }^{29}$. Das OMI jedoch vertagte die Entscheidung über den Einsatz auf den 28. November ${ }^{30}$. Ebenso wurde die Entscheidung über den Beginn des zweiten Kurses auf diesen Termin verschoben ${ }^{31}$. Damit wurde die Parteischulung bereits nach dem ersten Kurs bis zur weiteren Klärung durch das OMI ausgesetzt. Dies stand offenbar in Zusammenhang mit den alliierten Beratungen in der European Advisory Commission, die am 11. November 1944 mit einer Einigung über die Kapitulationsbedingungen für das Deutsche Reich, die Besatzungszonen und die alliierte Kontrolle in Deutschland zu einem Abschluß kamen. Über den mit diesen Vereinbarungen erreichten Status quo wurde dann erst wieder auf der alliierten Konferenz von Jalta im Februar 1945 verhandelt $^{32}$. Außenpolitisch wurde die sowjetische Deutschlandplanung Mitte November „faktisch einge-

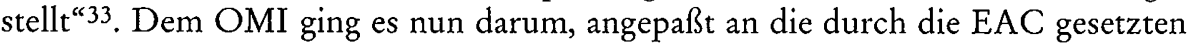
Rahmenbedingungen die deutschlandpolitischen Vorstellungen der Sowjetunion zu konkretisieren.

Mitte November forderte das OMI die Ergebnisse der Programmkommission der KPD ein, die parallel zu den sowjetischen Verhandlungen in der EAC seit dem Frühjahr 1944 getagt hatte. Das Abschlußpapier war unter dem Titel „Programm des Blockes der kämpferischen Demokratie" im Laufe des Oktobers 1944 zusammengefaßt worden, wurde aber in Reaktion auf die alliierten Absprachen in der EAC überarbeitet. Die vierte, endgültige Fassung wurde am 28. November im OMI diskutiert ${ }^{34}$. Inhaltlich unterschieden sich die Entwürfe von der Endfassung vor allem dadurch, daß diese noch von einem „Sofortprogramm unter den Bedingungen der militärischen Besetzung “ ausgegangen waren, in der Schlußfassung dagegen nur noch allgemein gehaltene „Forderungen des Blockes der kämpferischen Demokratie für einzelne Gebiete des öffentlichen Lebens" aufgestellt wurden ${ }^{35}$. Das Programm hatte einen vollkommen anderen Charakter bekommen. Ursprünglich war es, einer Notiz Anton Ackermanns aus dem Jahre 1964 zufolge, gedacht gewesen „als Aktionsprogramm überparteilicher Art für alle Besatzungszonen in Deutsch-

29 Pieck an Dimitrov am 1.11. 1944, RGASPI 495/74/154, Bl. 117; Liste mit Namen und Einsatzgebieten, ebenda Akte 161, Bl. 158-159, vgl. Liste der Absolventen des ersten Kurses, SAPMO-BArch NY 4036/530, Bl. 107.

30 Auf der von Pieck eingereichten Liste machte die Kanzlei des OMI den handschriftlichen Vermerk „die Frage wird auf der Sitzung bei Genosse Dimitrov am 28.11.44 entschieden“, RGASPI 495/74/161, Bl. 159.

31 Aufstellung über Lehrer und Schüler für den 2. Kurs an der Schule Nr. 12, RGASPI 495/74/161, Bl. 150-151.

32 Kowalski, Die „European Advisory Commission“, S. $279 \mathrm{ff}$

33 Einleitung von Laufer/Kynin, in: SSSR i germanskij vopros, tom I, S. 39.

34 Rekonstruktion der Chronologie in „Nach Hitler kommen wir“, S. 93 ff.; siehe auch Morré, Kommunistische Emigranten, S. $289 \mathrm{ff}$.

35 „Aktionsprogramm des Blockes der kämpferischen Demokratie“, in: „Nach Hitler kommen wir", S. 292; vgl. die vorherigen Versionen, ebenda, S. 241 f., 244 f. und $266 \mathrm{ff}$. 
land“36; nun war es die Einstimmung auf ein alliiertes Besatzungsregime. Diese veränderte Herangehensweise der KPD an die Nachkriegsplanung war schon in den Wochen zuvor angeklungen, als Pieck vor den Schülern der Schule Nr. 12 erläuterte: „Dabei müssen wir natürlich berücksichtigen, daß Deutschland militärisch besetzt sein wird, daß also vorläufig von der Wahl eines Parlaments und der Bildung einer Regierung keine Rede sein wird, ja sogar ein einheitliches inneres Regime nicht geschaffen wird. Trotzdem muß das Aktionsprogramm doch die politischen Grundgedanken enthalten, die der Block der kämpferischen Demokratie vertritt und für die er kämpft. Es handelt sich also weniger um Forderungen als um Erklärungen, was das deutsche Volk an die Stelle des Hitlerismus setzen will, was das neue Deutschland sein soll." 37

Was als konkrete Vorbereitung im Laufe des Jahres 1944 begonnen worden war, wurde gegen Jahresende erheblich eingeschränkt. Nicht nur das Programm der KPD wurde in der Verbindlichkeit seiner Aussagen relativiert, auch die Auswahl und Schulung von Kadern ging nicht weiter voran. Nach Abschluß des ersten Kurses wartete die Leitung der Schule Nr. 12 auf weitere Instruktionen. Pieck drängte Dimitrov zu einem Besprechungstermin. In seinem Brief vom 25. November 1944 präsentierte er ein ganzes Bündel anstehender Entscheidungen: (1) die Frage der Herausgabe „konkreter Kampfaufgaben“, (2) die Frage nach dem Einsatz der Absolventen der Parteischule und (3) die Fortsetzung der Parteischulung. Als weiteren ungeklärten Punkt warf Pieck (4) die Frage nach dem Einsatz der KPD-Mitglieder und ausgewählter Kriegsgefangener unter einem sowjetischen Besatzungsregime auf. D. h. im Unterschied zu dem geplanten „illegalen“ Einsatz der in der „Schule Nr. 12" bereits ausgebildeten Kader sollte auch die Kaderauswahl für einen Einsatz unter "legalen Bedingungen“ getroffen werden. Piecks vorgebrachte Fragen sollten am 28. November im OMI beantwortet werden ${ }^{38}$.

Über die Besprechung am 28. November 1944 liegen leider keine Dokumente, auch keine Aufzeichnungen Piecks vor. Lediglich das von Dimitrov oder der Kanzlei des OMI bearbeitete Schreiben Piecks vom 25. November, in dem er die Tagesordnung für die Sitzung vorschlug, gibt einen Hinweis auf die Haltung des OMI. Gestrichen waren die Tagesordnungspunkte über die Veröffentlichung von „Kampfaufgaben“, den Einsatz der Parteischüler und den zweiten Kurs der Schule Nr. 12. Und tatsächlich wurde das deutschlandpolitische Programm der KPD nicht veröffentlicht, die Parteischüler des ersten Kurses nicht eingesetzt und die Arbeit der Schule Nr. 12 unterbrochen. Dagegen waren die Punkte auf der Tagesordnung nicht gestrichen worden, die sich auf den Kadereinsatz in Deutschland unter alliierter Besatzung bezogen. Diese waren: „Vorbereitung des Einsatzes kommunistischer Kader für die Aufgaben im Lande unter legalen Bedingungen“, „Auswahl von entwicklungsfähigen kommunistischen und antifaschistischen Kadern in den Kriegsgefangenenlagern zur Vorbereitung für Aufgaben in Deutschland unter legalen Bedingungen“ und „Durchführung des beschlossenen Literaturplanes“39. Damit rückte

36 Ebenda, S. 290, Anm. 166.

37 Piecks Rededisposition zum Aktionsprogramm der KPD, vorgetragen am 18. 10. 1944 in der Schule Nr. 12, ebenda, S. 263.

38 Pieck an Dimitrov am 25. 11. 1944, RGASPI 495/74/161, Bl. 149; ebenda handschriftlicher Kanzleivermerk, daß die Entscheidung auf den 28. 11. 1944 vertagt werde.

39 Ebenda. 
die Vorbereitung der Besatzungsverwaltung in der zukünftigen sowjetischen Besatzungszone in Deutschland in das Zentrum der weiteren Tätigkeit des Instituts 99.

Die Vorbereitung auf eine „legale“ Tätigkeit kommunistischer Kader unter alliierter Besatzung war mit der sogenannten Abendschule geplant worden. Diese sollte parallel zu der Schule Nr. 12 die in Moskauer Einrichtungen des ZK der VKP (b) - hauptsächlich in den „Instituten“ des OMI - arbeitenden KPD-Mitglieder entsprechend ausbilden. Damit war vom OMI eine zweigleisige Strategie gewählt worden. Am 5. Oktober, der erste Kurs in Schodna war gerade angelaufen, hatte Pieck Themenplan und Teilnehmerliste für die „Abendschule“ in den Räumen des Instituts 99 an Dimitrov geschickt. Geplant war, mit den Moskauer Spitzenfunktionären der KPD in wöchentlichen Vorträgen das gleiche Programm wie in der Schule Nr. 12 in geraffter Form durchzuarbeiten ${ }^{40}$. Aber die Abendschule begann erst nach der Entscheidung des OMI vom 28. November. Nun erst, in der Zeit vom 10. Dezember 1944 bis zum 4. März 1945, wurde die Vorbereitung „legaler Kader“ begonnen. Die ursprünglich ausgewählte Gruppe von KPD-Mitgliedern - im Oktober waren 73 nominiert worden - wurde geteilt und geringfügig erweitert. An den Abendvorträgen im Institut 99 nahmen 52 „einfache Mitglieder" teil. Parallel dazu kam der „engere Zirkel“ von 34 Personen im Hotel Lux, dem Wohnheim der Emigranten, zusammen. Dieser Zirkel bestand überwiegend aus den ehemaligen Kominternfunktionären der KPD, die nun in den Instituten 99 und 205 arbeiteten ${ }^{41}$. Verteilt auf elf Vortragsabende und drei Seminare zur Vertiefung des Stoffes behandelte das Programm die Geschichte des Imperialismus und des Faschismus, die Geschichte der Sowjetunion und der KPdSU, die Politik der KPD seit der Weimarer Republik. Und es ging auf die kommende Agrar-, Gewerkschafts- und Parteipolitik im Sinne des Blockes der kämpferischen Demokratie („Aufgaben der Kommunisten") ein ${ }^{42}$.

Die Aufteilung der Parteischüler auf die „Schule Nr. 12“, die Abendschule im Institut 99 und den „engeren Zirkel“ im Hotel Lux korrelierte mit der Kaderaufstellung der KPD, die dem OMI am 28. November 1944 als „Vorschläge zur Vorbereitung leitender Kader" präsentiert worden waren ${ }^{43}$. Darin wurden namentlich 257 Politemigranten für die Besetzung von Ämtern im Staats- und Parteiapparat vorgeschlagen. Quantitativ stand der Aufbau des Parteiapparates im Vordergrund. Es wurden 37 Funktionäre für den zentralen Parteiapparat, 59 für die Beset-

40 Pieck an Dimitrov am 5. 10. 1944, RGASPI 495/74/161, Bl. 113; ebenda Bl. 114: „Liste der Kursusteilnehmer im Haus Obucha Nr. 6 [Institut 99]; ebenda Bl. 144-146: „Themenplan für den Abendkursus“.

41 Teilnehmerliste mit 73 Namen vom 5. 10. 1944, RGASPI 495/74/161, Bl. 114; „Liste der Kursus-Teilnehmer (Abendkurs)" mit 50 Namen, SAPMO-BArch NY 4036/531, Bl. 7; Feststellung der Teilnahme von 52 Personen bei Abschluß der Abendschule am 4.3. 1945, ebenda Bl. 26; Aufstellung über den „engeren Zirkel“ vom 5. 12. 1944, SAPMO-BArch NY 4036/531, Bl. 8; die Teilnehmerliste für beide Zirkel ist wiedergegeben bei Tischler, Flucht in die Verfolgung, S. 221, Anm. 142; Tischler führt die Verzögerung der „Abendschule“ auf Raumprobleme zurück.

42 Vgl. "Themenplan für den Abendkursus" (Vorlage vom 5. 10. 1944), RGASPI 495/74/161, Bl. 144-145 (inhaltlich identisch mit dem Exemplar im SAPMO-BArch NY 4036/531, Bl. 2-3); vgl. Notizen Piecks über Eröffnung (10.12. 1944) und Abschluß (4. 3. 1945) des Vorbereitungskurses, SAPMO-BArch NY 4036/531, Bl. 9-14 und Bl. 25-27.

43 „Vorschläge zur Vorbereitung leitender Kader“", RGASPI 495/74/161, Bl. 146-148. 
zung der Bezirksleitungen, 100 „Genossen, die zur Verfügung des ZK stehen“ und ohne namentliche Nennung - „ca. 50 Genossen für untergeordnete Funktionen“ benannt. Demgegenüber wurden lediglich 38 Emigranten für die Übernahme von Ämtern im Staatsapparat und 23 für den Einsatz in Massenorganisationen (Gewerkschaften, Jugend-, Bauern-, Schriftsteller- und Sportverbände, Genossenschaften und Volkshilfe) eingeplant. Diese sollten jedoch alle einflußreichen Regierungsressorts besetzen ${ }^{44}$. Die Aufstellung berücksichtigte ausschließlich kommunistische Emigranten ${ }^{45}$ bzw. geschulte Kriegsgefangene, aber keine Parteimitglieder in Deutschland. Ganz offensichtlich berücksichtigte die Exilführung der KPD möglichst alle Spitzenpositionen im zukünftigen Partei- und Regierungsapparat mit zuvor in Moskau vorbereiteten Kadern zu besetzen. Im „engeren Zirkel“ wurden die Funktionäre für den zentralen Parteiapparat, die zukünftigen Inhaber staatlicher Ämter dagegen im „Abendkurs“ geschult. Die Absolventen der Schule Nr. 12 wurden vorwiegend für den Parteiapparat in den „Hauptgebieten“ Nordwest- (Ruhrgebiet, Hamburg, Bremen), Südwest- (Frankfurt, Mannheim, Stuttgart, Nürnberg, München), Mittel- (Thüringen, Halle-Merseburg) und Ostdeutschland (Berlin, Sachsen, Magdeburg, Schlesien, Pommern-Mecklenburg) eingeplant ${ }^{46}$. Die Kaderplanung der KPD sah demzufolge vor, den regionalen Parteiapparat noch vor der alliierten Besetzung - unter „illegalen Bedingungen“ - zu errichten, während die reichsweite Parteizentrale erst nach der Okkupation - unter „legalen Bedingungen“ - gebildet werden sollte. Auf jeden Fall hatte der Aufbau der Partei absoluten Vorrang vor der Besetzung von Ämtern in der staatlichen Verwaltung47. Die Ende 1944 bereits abzusehende Aufteilung Deutschlands in Besatzungszonen, über die in der EAC beraten worden war, wurde in der Kaderaufstellung nicht berücksichtigt, sondern die Stellenbesetzungen reichsweit geplant.

Die im Dezember 1944 begonnenen Schulungen im Institut 99 galten ausschließlich der Vorbereitung auf die Besetzung von Partei- und Verwaltungsposten in Deutschland unter den Bedingungen alliierter Okkupation, d.h. unter „legalen Bedingungen“. Die Abendschulung war nicht für einen konkreten Einsatz gedacht. Auf einen Zeitpunkt wollte und konnte sich das OMI nicht festlegen. So sprach Wilhelm Pieck in der Eröffnungssitzung der Abendschule lediglich von der „Möglichkeit, daß sich sehr schnell die Lage zu einer ernsten Krise des Naziregimes zuspitzt $^{\text {" } 48}$. Diese vorsichtige Formulierung wird die Konsequenz aus der Entscheidung des OMI vom 28. November gewesen sein. Die Vorbereitung auf einen „lega-

44 Im Staatsapparat sollten die Ressorts „Arbeitsbeschaffung und Demobilmachung“, „Wiedergutmachung“, „Wirtschaft, Finanzen, Steuern“, "Wohnungs- und Kommunalpolitik“, „Schule und Erziehung“, „Radio“, „Film, Theater, Freizeitgestaltung“, „Sozialfürsorge, Gesundheitswesen", „Eisenbahn,Verkehr und Post" und "Rechtswesen" mit kommunistischen Funktionären besetzt werden.

45 Bis auf 36 Spitzenfunktionäre befanden sich alle im sowjetischen Exil.

46 Das ergibt ein namentlicher Vergleich der hier vorgestellten Kaderaufstellung mit den Teilnchmern an den Schulungen, die im Anhang genannt werden.

47 Vgl. Erler (Heerschau und Einsatzplanung, S. 60) zu den Kaderplanungen der KPD Anfang 1944: „Die Tatsache, daß die Moskauer Führung in ihrem Selbstverständnis bereits davon ausging, die KPD würde zukünftig eine staatstragende Partei sein, kommt nicht zum Ausdruck. Eine Orientierung auf den Einsatz in Bereichen von Staat, Verwaltung und Wirtschaft fehlt völlig."

48 Notizen Piecks für die Eröffnungsrede am 10. 12. 1944, SAPMO-BArch NY 4036/531, Bl. 9. 
len Einsatz" galt nun auch für die Schule Nr. 12. Parallel zu dem Abendkurs im Institut 99 wurde die Nominierung der Schüler für den zweiten Kurs, die bereits im September 1944 begonnen hatte $e^{49}$, wieder aufgenommen.

Wegen der Auswahl des zweiten Kurses an der Schule Nr. 12 kam es zum heftigen Streit zwischen KPD und Institut 99. Auslöser war, daß die KPD die Kaderrekrutierung unter den Kriegsgefangenen kaum beeinflussen konnte. Zwar versuchte sie, über die Politinstrukteure in den Lagern aktiv auf die Auswahl einzuwirken ${ }^{50}$, aber mehr als ein persönliches Gespräch mit dem Kandidaten im Lager konnte damit nicht erreicht werden. Für die sowjetischen Anforderungen an eine Kaderentscheidung reichte das nicht aus. Försterling, der Kaderleiter des KPD-Auslandsbüros, war auf das Entgegenkommen des Instituts 99 angewiesen, das über die Kaderunterlagen der Kriegsgefangenen verfügte. Aber Kozlov gewährte diesen Einblick nicht. Ebensowenig gelang es der KPD, die von ihr gewünschten Parteimitglieder zur Schulung heranzuziehen. Das Bestreben der KPD war es, zum Ausbau der eigenen Kaderbasis die weit verstreut in der Sowjetunion lebenden Emigranten, vor allem die „bewährten Genossen“, die als Politinstrukteure in den Lagern oder als Lehrer in den Antifa-Schulen arbeiteten, zur Parteischulung nach Moskau zu holen. Das Institut 99 dagegen wählte bevorzugt ehemalige Kominternfunktionäre aus, die in den Moskauer Apparaten arbeiteten und - so Kozlov - bereits über die notwendige Organisationserfahrung verfügten. Försterling beschwerte sich bei Dimitrov: „Genosse Kozlov, der zukünftige Vorsitzende der Kommission für die Angelegenheiten der Schule Nr. 12, wird dieser Aufgabe nicht gerecht. Eine Reihe von Genossen, die von uns schon als Hörer für den ersten Kurs vorgeschlagen worden waren, wurde nicht angefordert, so daß der zivile Teil mit Mitarbeitern aus dem Moskauer Apparat ergänzt werden mußte. Auf meine nachdrückliche Aufforderung bereits vor einigen Wochen, sich ernsthaft mit der Freistellung der durch die Aufnahmekommission berufenen Hörer (zivile) des zweiten Kurses zu beschäftigen, die für das NKVD oder das GlavPURKKA arbeiten (Genossen Scheib, Abraham, Dohm, Welker-Börner), hat er es abgelehnt, irgendetwas zu unternehmen. Er berief sich darauf, daß dies eine Angelegenheit Guljaevs [OMI] sei und daß er viele andere Dinge zu erledigen und keine Zeit habe." 51

Das Institut 99 umging bewußt das Problem, diejenigen kommunistischen Emigranten für die Parteischulung anzufordern, die als Politinstrukteure in den Kriegsgefangenenlagern arbeiteten. Denn da diese dort dringend für die politische Arbeit unter den Kriegsgefangenen gebraucht wurden, hätte ihre Abberufung den Protest des UPVI hervorgerufen. Diesem Konflikt ging Kozlov aus dem Weg, indem er sich auf die Kaderverwaltung des NKVD berief, auf die er keinen Einfluß nehmen könne. Bei der Auswahl der Kriegsgefangenen dagegen hielt er am Monopol des Instituts 99 fest. Auf die Anschuldigungen Försterlings entgegnete er, die KPD könne nicht an der Kaderentscheidung beteiligt werden, da sie die dafür notwendigen Unterlagen nicht kenne: „Den Grund für das Auftreten Försterlings mit unvorbereite-

49 Vgl. Pieck an Dimitrov am 26. 9. 1944, SAPMO-BArch NY 4036/544, Bl. 53-54.

50 Vgl. "Zur Charakteristik der Schüler aus Schule 12“ an Kijatkin (Leiter der Antifa-Schule in Juža), ohne Datum, SAPMO-BArch NY 4091/87, B1. 22. Wahrscheinlich wurden die Kriterien von Bernhard Koenen, dem deutschen Sektorleiter an der Antifa-Schule Juža, im Herbst 1944 formuliert.

51 Försterling an Dimitrov am 6. 12. 1944, RGASPI 495/77/39, B1. 42-44. 
tem Material [unvollständigen Kaderunterlagen] sehe ich darin, daß er Material über die deutschen Kader erhalten und das Institut umgehen will, indem er uns lediglich die technische Seite (Überstellung der Kriegsgefangenen) überläßt, da er selbst mit dieser Aufgabe nicht fertig wird. Er wird diese Aufgabe auch nicht bewältigen können, da er keine Quellen hat, die ihn mit Material versorgen. Seine einzige Möglichkeit sind zufällige Gespräche mit den über Moskau reisenden deutschen Politinstrukteuren. Ich muß Sie [Dimitrov] darauf hinweisen, daß die systematische Befragung im Lux [Wohnheim der KPD-Emigranten in Moskau] von zufällig durchreisenden Politinstrukteuren über die Lage in den Lagern auf Widerstände der Lagerverwaltung des NKVD [UPVI] stößt." 52 Auf die Auswahl kriegsgefangener Parteischüler konnte das Institut 99 wesentlich stärker einwirken, da ihm die Registrierung "antifaschistischer Kriegsgefangener" oblag. Die Emigranten aber waren für die Kaderverwaltung des Instituts 99 nicht erreichbar.

Die Streitigkeiten zwischen KPD und Institut 99 spiegeln sich in der tatsächlichen Zusammensetzung der ersten beiden Kurse an der Schule Nr. 12 wider. Für den ersten Kurs waren insgesamt 36 Kriegsgefangene und 27 Emigranten vorgeschlagen worden, absolviert haben ihn lediglich 20 Kriegsgefangene und 11 Emigranten. Die meisten Nominierungen wurden für den zweiten Kurs wiederholt ${ }^{53}$. Der zweite Kurs begann am 9. Januar und dauerte bis zum 18. März 194554. Im Grunde bestand er aus denjenigen, die bereits für den ersten Kurs vorgeschlagen, aber nicht aufgenommen worden waren. Wie beim ersten Durchgang wurde auch dieser Kurs auf einen reichsweiten Einsatz vorbereitet: Die „1. Gruppe“ mit den Einsatzgebieten Berlin/Brandenburg, Schlesien, Ostpreußen, Hamburg und Sachsen und die „2. Gruppe“ in Thüringen, Süd- und Westdeutschland ${ }^{55}$. Das waren die „Hauptgebiete“, die die KPD für den Aufbau des Parteiapparates vorgesehen hatte. Allerdings hatten sich die Rahmenbedingungen geändert. So lange es keine konkreten alliierten Absprachen über das Besatzungsregime gab, blieb der Zeitpunkt des Einsatzes der geschulten Kader offen. Die Absolventen des ersten Kurses befanden sich nach wie vor in Nagornoe, wo sie ungeduldig warteten ${ }^{56}$.

Das OMI stoppte die Vorbereitung auf den „illegalen“ Kadereinsatz in Deutschland. Es wurde nur noch auf die Übernahme von Verwaltungsposten und Parteifunktionen in Deutschland unter regulären („legalen“) Bedingungen einer alliierten Besetzung vorbereitet. Bis Anfang Februar 1945 wurde das gesamte Reichsgebiet in die Kaderplanungen einbezogen. Damit waren keine weitergehenden Okkupationspläne intendiert, sondern diese Planung war vermutlich auf die Annahme zurückzuführen, die Rote Armee werde wesentlich weiter nach Westen vorstoßen, als sie das dann tatsächlich tat. Alle Maßnahmen hinsichtlich einer zukünftigen Besatzungsverwaltung wurden vom OMI eher zögerlich ergriffen. Es wurden nicht, wie von der KPD gewünscht, „konkrete Kampfaufgaben“ oder ein „Sofortprogramm“ verabschiedet. Die planerischen Vorbereitungen, die in Form des „Aktionsprogrammes

52 Kozlov an Dimitrov am 10. 12. 1944, RGASPI 495/77/39, Bl. 39-41.

53 Siehe Anlage Nr. 2.

54 „Bericht über den deutschen Parteikursus“, SAPMO-BArch NY 4036/500, B1. 121.

55 Aufstellung von Försterling vom 8. 1. 1945, SAPMO-BArch NY 4036/530, B1. 90-92. Die beiden Gruppen beziehen sich auf die Seminargruppen an der Schule Nr. 12, eine dritte (Thüringen, Sachsen, Schlesien) war geplant.

56 Vgl. Pieck an Dimitrov am 14. 12. 1944, RGASPI 495/77/162, Bl. 92. 
des Blocks der kämpferischen Demokratie" komplett vorlagen, wurden zurückgestellt ${ }^{57}$. Statt dessen griff das OMI auf die durch das Nationalkomitee vorhandenen Ansätze sowjetischer Deutschlandpolitik zurück.

\section{Kommissionen des Nationalkomitees}

Einen Tag nachdem der „illegale“ Kadereinsatz aufgeschoben worden war, wurde am 29. November im OMI über die weitere Arbeit im Nationalkomitee beraten. Als Vorlage diente eine Aufstellung „Über die Vorbereitung antifaschistischer Kriegsgefangener für Aufgaben in Deutschland", die vermutlich unmittelbar nach der Sitzung bei Dimitrov vom Vortag ausgearbeitet worden war. In enger Anlehnung an die Themen der KPD-Arbeitskommission sollten nun auch innerhalb des Nationalkomitees entsprechende Arbeitsgruppen gebildet werden. Vorgesehen war die Bearbeitung der Fragen einer Schul- und Agrarreform, der Umstellung der Wirtschaft, der Kommunal- und Jugendpolitik, der Entnazifizierung von Kunst und Literatur sowie der generellen Entnazifizierung des deutschen Volkes („Liquidierung der Rassenideologie"). Offensichtliches Ziel war es dabei, durch die Arbeitsgruppen des NKFD Fachleute heranzuziehen: „Es ist notwendig, die antifaschistischen Fachkräfte unter den Kriegsgefangenen im Prozeß der Arbeit zu prüfen und sie bei uns zu registrieren." 58 Das OMI besann sich mit diesem Beschluß auf Initiativen, die vom Institut 99 seit dem Frühjahr 1944 betrieben worden waren, wenn auch ohne den notwendigen Nachdruck.

Erste Überlegungen zu Fragen einer Schulreform in Deutschland nach dem Krieg hatte es im Zusammenhang mit der Arbeit der KPD-Arbeitskommission im April 1944 gegeben. Erich Weinert sollte sich in seiner Eigenschaft als Mitglied der KPDKommission sowie in Personalunion mit dem Amt des Präsidenten des NKFD mit Fragen der „ideologischen Umerziehung des deutschen Volkes“ beschäftigen ${ }^{59}$. Gleichzeitig begann eine beim Institut 99 angesiedelte „Übersetzergruppe“ (Noffke, Wendt) sowjetische Standardwerke aus den Bereichen Philosophie, Pädagogik und Naturwissenschaften ins Deutsche zu übertragen sowie Schulbücher der Rußlanddeutschen aus der Wolgarepublik für den Gebrauch in Deutschland zu bearbeiten. Auf diese Weise sollte Ersatz für die nationalsozialistischen Schulbücher und eine Grundlage für die Lehrerumschulung nach dem Krieg geschaffen werden ${ }^{60}$. Diese Arbeiten kamen aber nicht richtig in Gang und blieben bis zum Sommer 1944 liegen. Erst nach der Gründung des OMI beschloß das Institut 99 am

57 Vgl. Erler/Laude/Wilke („Nach Hitler kommen wir“, S. 98), die auf die Frage, warum das Aktionsprogramm nicht veröffentlicht wurde, antworten, daß das gemeinsame Vorgehen der Alliierten nicht gefährdet werden sollte. Siehe demgegenüber Fischer (Sowjetische Deutschlandpolitik, S. 119), daß der durch die Beschlüsse der EAC gesetzte Rahmen mit dem Programm des Blockes der kämpferischen Demokratie gefüllt worden sei.

58 „Über die Vorbereitungen antifaschistischer Kriegsgefangener für Aufgaben in Deutschland" vom 28. 11. 1944, RGASPI 495/74/161, Bl. 161. Die Vorlage trägt den handschriftlichen Vermerk „Die Frage wird am 29. 11. 44 auf der Sitzung bei Genosse Dimitrov beraten."

59 Vgl. Arbeitsplan der Kommission, in: „Nach Hitler kommen wir“, S. 134.

60 Notizen Piecks vom 12. 4. 1944 von einer Besprechung mit Ulbricht, Ackermann, Noffke, Bolz, Hörnle, Willmann und Wendt, SAPMO-BArch NY 4036/499, Bl. 108-113. 
10. Juli 1944, eine „Broschürenredaktion“ (Rudolf Herrnstadt, Willi Bredel, Peter Florin und Dora Gordeeva) einzusetzen und für die Fertigstellung der im April begonnenen Übersetzungen zu sorgen ${ }^{61}$. Nach Rücksprache mit Dimitrov wurde vom Institut 99 am 14. August eine Erweiterung des Redaktionskollegiums beschlossen ${ }^{62}$. In die als „Broschürenreihe des Nationalkomitees“ titulierte Publikationsserie sollten - das war neu - nun auch kriegsgefangene Autoren aufgenommen werden ${ }^{63}$. In Analogie zu den zweigeteilten Radio- und Zeitungsredaktionen des NKFD setzte das Institut 99 eine Kommission zur Erstellung eines ,antifaschistischen Schulbuches" ein. Mitglieder waren die Kriegsgefangenen Hadermann, Kertzscher und Rücker - alle im Zivilberuf Lehrer - und Johannes R. Becher, der sich in der KPD-Kommission mit der Kulturpolitik beschäftigte ${ }^{64}$. Damit waren die aus der Arbeitskommission der KPD erwachsenen Ansätze personell mit den Aktivitäten des NKFD vermengt worden.

Im Spätsommer 1944 wurde im Institut 99 ein ausführlicher Literaturplan entworfen, der eine „Schriftenreihe des Nationalkomitees“ mit 16 Bänden und eine „Schriftenreihe der KPD“ mit ca. 75 Bänden vorsah. Pieck bezeichnete die ausgewählte Literatur als diejenige, „die am dringlichsten in Deutschland für die Mobilisierung der Massen zum Kampf gegen den Hitlerismus, für ihre Loslösung und Umerziehung und für die Schaffung eines demokratischen Deutschlands benötigt wird“. ${ }^{65} \mathrm{Da}$ der Literaturplan aber zu einem großen Teil ganz allgemein Klassiker des Marxismus-Leninismus (4 Bände Marx, 1 Band Engels, 12 Bände Lenin, 8 Bände Stalin) und Werke „antifaschistischer Schriftsteller“ (Bredel, Weinert, Wolf, Plivier, Scharrer) umfaßte, mahnte Dimitrov an, sich auf einige der wichtigsten Titel zu konzentrieren. Dimitrov erinnerte an die Einbeziehung der kriegsgefangenen Autoren in die Schriftenreihe. Im Gespräch waren die Generäle Seydlitz, Hoffmeister und Lattmann, Wehrmachtspfarrer Krummacher sowie die Offiziere Bechler und Rudi Pallas ${ }^{66}$. Am 18. September beschloß der Zivilsektor im Institut $99 \mathrm{zu}-$ dem, eine Delegation in das Offizierslager Nr. 150 (Grjazovec) zu schicken, um dort unter der Leitung des Mitglieds der "Schulbuchkommission“ Rücker eine "Lehrergruppe“ aufzubauen ${ }^{67}$. Dem OMI konnte darüber am 29. November berichtet werden: „Über die Schulfragen fanden bereits einige Beratungen statt. Im Offizierslager Nr. 150 wurde eine Besprechung mit 100 Lehrern durchgeführt. “68

Ein anderer Anknüpfungspunkt für die Bildung von Arbeitsgruppen aus Mitgliedern des Nationalkomitees war die „innere Schulung“, die nach Beilegung der Krise

61 Beschlußprotokoll des Instituts 99 vom 17.7. 1944, RGASPI 495/77/46, BI. 6; Notizen Piecks vom 17. 7. 1944, SAPMO-BArch NY 4036/499, Bl. 152.

62 Notizen Piecks „Ausführung der Beschlüsse vom 9. 8. 1944“, in: „Gruppe Ulbricht“, S. 122.

63 Als kriegsgefangene Autoren waren Seydlitz, Hoffmeister, Krummacher, Lattmann und Pallas vorgesehen.

64 Protokoll des Instituts 99 vom 14. 8. 1944, RGASPI 495/77/46, Bl. 12-13.

65 „Entwurf eines Planes für die Herausgabe von Literatur“, SAPMO-BArch NY 4036/499, Bl. 156-160. Der Literaturplan wurde am 15.8. 1944 von Pieck an Dimitrov geschickt, ebenda Akte 544, Bl. 46.

66 Notizen Piecks von einer Besprechung am 9. 9. 1944 bei Dimitrov, in: „Gruppe Ulbricht“, S. 128.

67 Beschlußprotokoll des Instituts 99 vom 18. 9. 1944, RGASPI 495/77/46, Bl. 21.

68 „Über die Vorbereitung antifaschistischer Kriegsgefangener für Aufgaben in Deutschland“ vom 28. 11. 1944, RGASPI 495/74/161, Bl. 161. 
um das Seydlitz-Memorandum am 10. April 1944 im Institut 99 beschlossen worden war: „Änderung in der Spitze des BDO - noch nicht befriedigend - mehr ideologisch bearbeiten. “69 Als erste Maßnahme wurde im Sommer 1944 eine Gruppe von NKFD-Mitgliedern in der Antifa-Schule Krasnogorsk geschult, um anschließend im Lager Lunevo auf die übrigen Komiteemitglieder einzuwirken. Hauptmann Dengler, der wie auch NKFD-Vizepräsident Einsiedel zu diesen AntifaSchülern gehörte, beschrieb das mit den Worten: „An Hinweisen der KPD-Genossen merkten wir, daß man von uns vor allem erwartete, in Gesprächen und Diskussionen mit den so unterschiedlichen Mitgliedern des NKFD in Lunowo daran mitzuwirken, daß ihre politische Entwicklung mit der sich rasch verändernden Lage Schritt hielt, daß wir uns also an einer Art von ,innerer Schulung' beteiligten."70 Einsiedel dagegen stellte „innere Schulung “ in die Nähe von Spitzeldiensten, die die Antifa-Absolventen im Lager Lunevo zu leisten gehabt hätten ${ }^{71}$. Aber auch wenn es diese Form der Beeinflussung immer gegeben hat, so entschied das Institut 99, die innere Schulung des Nationalkomitees über Privatgespräche und Vorträge zu organisieren, die im Haus des Nationalkomitees in Lunevo („Objekt Nr. 15“) und im Generalslager in Voikovo („Objekt Nr. 20“) regelmäßig abgehalten werden soll$\operatorname{ten}^{72}$. Als Vortragsthemen für die Mitglieder des Nationalkomitees in Lunevo wurden folgende Titel aufgestellt: „a) Sowjetdemokratie in der Praxis, b) Sozialistische Planwirtschaft, c) Aus dem Leben der Kollektivwirtschaften, d) Sowjetwissenschaft und Sowjetliteratur, e) Die gegenwärtige Krise in Deutschland, f) Aus der Vergangenheit der deutschen Arbeiterbewegung, g) Die Lehren von 1918“. Die Vorträge wurden von sowjetischen Politoffizieren und deutschen Kommunisten gehalten ${ }^{73}$. Die im Sommer 1944 neu für den BDO gewonnenen Generäle im Lager Voikovo hörten ebenfalls Vorträge. Hier waren die Referenten jedoch kriegsgefangene Offiziere, die sich vornehmlich mit dem Nationalsozialismus auseinandersetzten: Hauptmann Hadermann sprach über „Der Charakter des Hitlerkrieges“, Hauptmann Fleischer über „Die Wirtschaft unter dem Hitlersystem“ und Generalmajor von Lenski zu dem Thema „Der deutsche Imperialismus“. Ergänzt wurden diese Lesungen von einer Vortragsreihe des sowjetischen Politinstrukteurs „Professor Arnold"74. Ab September 1944 wurde eine stärkere Angleichung an das Programm der Antifa-Schule intendiert: „Zur Verstärkung unserer Schulungsarbeit im Hause des Nationalkomitees sollen in den nächsten Wochen einige antifaschistische Lektionen mit anschließender Diskussion gehalten werden. Als Referenten sollen Lektoren aus dem Lager 27 [Antifa-Schule Krasnogorsk] verwandt werden. "75

Ab Oktober 1944 wurde damit begonnen - so ein Beschluß des Instituts 99 -, die Mitglieder des Nationalkomitees auf die „Aufgaben in der Endphase des Krie-

69 Notizen Piecks vom 10. 4. 1944, SAPMO-BArch NY 4036/499, Bl. 101; vgl. Beschlußprotokoll des Instituts 99 vom 10. 4. 1944, RGASPI 495/77/46, Bl. 2-3.

70 Dengler, Zwei Leben in einem, S. 114.

71 Einsiedel, Tagebuch der Versuchung, S. $149 \mathrm{f}$.

72 Beschlußprotokoll des Instituts 99 vom 14. 8. 1944, RGASPI 495/77/46, Bl. 11; vgl. Puttkamer, Irrtum und Schuld, S. 75; Emendörfer, Rückkehr an die Front, S. 251.

73 Beschlußprotokoll des Instituts 99 vom 7. 8. 1944, RGASPI 495/77/46, Bl. 9.

74 Beschlußprotokoll des Instituts 99 vom 21. 8. 1944, ebenda, Bl. 15.

75 Beschlußprotokoll des Instituts 99 vom 4. 9. 1944, ebenda, Bl. 18. 
ges" einzustimmen 76 . In Vorbereitung auf die 14. Vollsitzung des NKFD wurde eine Kommission eingesetzt, „die sich mit den Fragen des Kampfes gegen die faschistische Ideologie in Deutschland und den Aufgaben des deutschen Volkes, die nach der Besetzung stehen, beschäftigen soll“77. General Korfes sollte als Mitglied dieser Kommission auf der Vollsitzung am 25. Oktober ein richtungsweisendes Referat halten. Auftragsgemäß beschäftigte er sich ausführlich mit dem Problem der "Vernichtung der nationalsozialistischen Ideologie“, wobei er versuchte, an die demokratischen Traditionen der Weimarer Republik anzuknüpfen. Aber das Ziel des Instituts 99, auf diesem Weg im Nationalkomitee eine Reflexion über den Nationalsozialismus und eine Diskussion über Fragen der Entnazifizierung zu initiieren, wurde nicht erreicht. Korfes ließ wenig Verantwortungsbewußtsein für die politische Entwicklung in Deutschland seit 1933 erkennen. So sei die „Wurzel der nationalsozialistischen Wirkung“ in der "Anlage des deutschen Volkes zur Aufnahmefähigkeit für den Rausch“ zu suchen. Das deutsche Volk sei getäuscht worden: „Diese verderbliche Macht hat über uns alle die Gewalt gewonnen, als der greise Feldmarschall und Reichspräsident bewogen wurde, dem Führer der nationalsozialistischen deutschen Arbeiterpartei, wie sie sich, schon in der Namensgebung lügend, nach eigener wohlüberlegter Wahl nannte, den höchsten deutschen Beamtenposten übergab. Die Mehrheit des deutschen Volkes, die weitaus größte Mehrheit sogar, sah diesen Regierungswechsel mit gemischten, bangenden, ja mit feindlichen Gefühlen entgegen. Die Begeisterung des Fackelzuges durch die Wilhelmstraße war nur beschränkt auf die, die dort im braunen Hemde marschierten, und auf die Anhänger, die auf den Bürgersteigen die Straßen säumten."

Korfes Referat löste eine heftige Diskussion zwischen den Kommunisten und den kriegsgefangenen NKFD-Mitgliedern aus. Dengler erinnert sich, daß dabei die Kommunisten für eine "tiefgreifende gesellschaftliche Umgestaltung" plädierten, weil ihnen die Konsequenzen, die Korfes gezogen hatte, nicht weit genug gingen: „Während einige NKFD-Mitglieder aus Lunewo die Umerziehung auf die Änderung einiger unter dem Nazisystem eingeführten faschistischen Erziehungsmethoden vor allem bei der Jugend reduzieren wollten, zeigte Wilhelm Pieck sehr überzeugend, daß die Ideologie der herrschenden Klasse immer die herrschende Ideologie ist, es also das kapitalistische System sei, das den Faschismus hervorgebracht und damit Millionen Deutsche infiziert habe. Die Umerziehung müsse daher in tiefgreifenden gesellschaftlichen Veränderungen wurzeln, wenn im deutschen Volk wirklich der Ungeist des Nationalsozialismus, des Chauvinismus, Rassisimus und Militarismus ausgerottet werden solle. "79 Die Kritik der Kommunisten hatte, unab-

76 Beschlußprotokoll des Instituts 99 vom 2. 10. 1944 über die Vorbereitung der 14. Vollsitzung des NKFD, ebenda, Bl. 23.

77 Beschlußprotokoll des Instituts 99 vom 9. 10. 1944, ebenda, Bl. 25. Als Kommissionsmitglieder waren Emendörfer, Hadermann, v. Lenski, Lattmann, Korfes, Rücker, Schröder, Kertzscher, Becher und Ulbricht vorgesehen.

78 „Vortrag des Generalmajors Dr. Otto Korfes auf der 14. Plenarsitzung des Nationalkomitees Freies Deutschland am 25. Oktober 1944: Die Vernichtung der nationalsozialistischen Ideologie“, SAPMO-BArch $90 \mathrm{KO}$ 10/30, Bl. 18 und 20; vgl. Wegner-Korfes, Weimar - Stalingrad - Berlin, S. $156 \mathrm{ff}$. Korfes Referat ist in der für die DDR-Geschichtsschreibung maßgeblichen Darstellung Weinerts nicht erwähnt, Weinert, Nationalkomitee, S. 96; ebenso Steidle, Nationalkomitee, S. 44.

79 Dengler, Zwei Leben in einem, S. 121. 
hängig von den weltanschaulichen Unterschieden, ihre Berechtigung. Denn die Offiziere des BDO scheinen sich im Herbst 1944 nur zögerlich an den Gedanken gewöhnt zu haben, daß ein gründliches Umdenken in Deutschland notwendig werden würde, um den Nationalsozialismus zu überwinden.

Bis zum Herbst 1944 waren - zumindest nominell - zwei Kommissionen des NKFD eingesetzt worden: die „Schulbuchkommission" unter Leitung von Leutnant Rücker und die „Kulturkommission“ zur Entnazifizierung der deutschen Gesellschaft unter General Korfes ${ }^{80}$. Als quasi dritte Kommission kann der „Arbeitskreis für kirchliche Fragen" hinzugezählt werden, der jedoch hauptsächlich wegen seines propagandistischen Effektes von Bedeutung war. So erläuterte Manuil'skij gegenüber Ščerbakov den Gründungsaufruf des kirchlichen Arbeitskreises: „Der Aufruf kann einen gewissen Einfluß auf religiöse Kreise in Deutschland haben. Auf der Grundlage dieses Aufrufes können wir eine stärkere Radiopropaganda, unterstützt durch Flugblätter und Broschüren, entwickeln. (...) Ich nehme an, daß das Auftreten deutscher Geistlicher einen für uns positiven Eindruck auch außerhalb Deutschlands, insbesondere in England und in den USA, macht." 81 Abgesehen von regelmäßigen Predigten über den Sender des Nationalkomitees scheint der Arbeitskreis keine eigenständigen Ausarbeitungen hervorgebracht $\mathrm{zu}$ haben ${ }^{82}$. Als vierte Arbeitsgruppe entstand - laut der Notizen Piecks - bereits auf der ersten Vollsitzung des NKFD am 14. Juli 1943 eine Wirtschaftskommission unter der Leitung von Hauptmann Fleischer ${ }^{83}$. Aber es lassen sich keine Spuren finden, die auf eine tatsächliche Tätigkeit dieser Kommission hinweisen. Insgesamt nennt Weinert in seinem Tätigkeitsbericht über das NKFD sogar fünf „Fachgruppen“: Wirtschaft, Sozialpolitik, Recht, Kultur und als spätere Gründung die Kommission für die Gebiete „faschistische Ideologie und reaktionäre Geschichtslügen“. Die Arbeitsgruppen seien durch die operative Abteilung des NKFD - d.h. das Institut 99 - gelenkt worden und hätten Schulungs- und Propagandamaterial ausgearbeitet ${ }^{84}$. In der Propaganda des NKFD spielten die Fachkommissionen jedoch keine Rolle ${ }^{85}$, und es scheint wenig wahrscheinlich, daß in den Kommissionen des NKFD vor dem Jahresbeginn 1945 konsequent inhaltlich gearbeitet worden ist.

Den fragmentarischen Charakter der inhaltlichen Arbeit im NKFD bzw. der vom Institut 99 gesteuerten Initiativen verdeutlicht die personelle Besetzung von Schulbuch- und Kulturkommission. Zum Teil hielten sich die nominierten Mitglieder gar nicht in Lunevo auf. Zudem stützen sich beide Kommissionen auf denselben Kreis von Aktivisten, so daß es sich faktisch um ein und dasselbe Gremium handelte ${ }^{86}$. Emendörfer brach Mitte Oktober 1944 zu einem Fronteinsatz auf, von dem

80 Vgl. Puttkamer, Irtum und Schuld, S. 75 und S. 85.

81 Manuil'skij an Šcerbakov am 30. 5. 1944, RGASPI 495/77/37, Bl. 29-30.

82 Vgl. Thme-Tuchel, Arbeitskreis für kirchliche Fragen, S. 70 ff.: Hinter den Artikeln und Aufrufen des kirchlichen Arbeitskreises sei „kein stringentes Schema zu erkennen“. Die Mitglieder des Arbeitskreises widmeten sich hauptsächlich der Organisation der Kriegsgefangenenseelsorge, ohne sich um ihre propagandistische Instrumentalisierung durch das NKFD zu kümmern; vgl. Puttkamer, Irrtum und Schuld, S. 71.

83 Notizen Piecks, „Daten der Bewegung“, SAPMO-BArch NY 4036/575, B1. 244.

84 Weinert, Nationalkomitee, S. $30 \mathrm{f}$.

85 Vgl. die Untersuchungen von Petrick, „Freies Deutschland“ und Diesener, Propagandaarbeit.

86 Hadermann, Kertzscher, Rücker, Becher in der "Schulbuchkommission“ und dieselben zu- 
er erst Ende Dezember 1944 wieder zurückkehrte ${ }^{87}$. Kommissionsmitglied Rücker besuchte von Oktober 1944 bis März 1945 die Antifa-Schule in Krasnogorsk ${ }^{88}$. Die schließlich von ihm geleitete „Schulbuchkommission“ nahm ihre eigentliche Arbeit erst im Februar 1945 auf. Nun bestand sie aus elf Mitgliedern, die einen klaren Auftrag erhalten hatten. Sie sollten Richtlinien für den Schulunterricht in deutscher Geschichte erstellen, die sowohl für die Gestaltung des Unterrichts als auch für die Umschulung der Lehrer verwendet werden könnten. Inhaltlich wurden die Planungen stark von dem Schulungsprogramm der Antifa-Schule beeinflußt, die Rücker soeben beendet hatte. Ein erster Entwurf der Unterrichtsrichtlinien wurde Mitte März fertiggestellt, die Arbeit der Kommission aber bis Ende Juli 1945 fortgesetzt ${ }^{89}$. Hadermann, der im August 1945 repatriiert wurde, soll den fertigen Richtlinienentwurf mit nach Deutschland genommen haben. Hadermann und Rücker, der ebenfalls im August 1945 repatriiert wurde, arbeiteten anschließend beide im Bildungswesen der SBZ/DDR 90 .

Ebenso wie die Schulbuchkommission, so kam auch die Umsetzung des vom Institut 99 im Herbst 1944 mit dem OMI abgestimmten Literaturplans erst im Frühjahr 1945 richtig in Gang. Ein Grund für die Verzögerung waren die fehlenden Bearbeiter. Rudolf Herrnstadt fiel wegen schwerer Krankheit bis zum Frühjahr 1945 aus, so daß im September 1944 Lothar Bolz die Leitung der Broschürenredaktion übernahm. In der Zeitungsredaktion, der nun der Chefredakteur fehlte, mußte Erich Weinert aushelfen ${ }^{91}$. Die somit permanent schwache Besetzung der Zeitungsund Radioredaktionen ließ das Institut 99 wiederholt auf die Verstärkung durch Kriegsgefangene drängen, wobei es vermutlich aber bei der Zweiteilung in Lagerund Stadtredaktion blieb ${ }^{92}$. Die Verzögerungen bei der Fertigstellung der vorgesehenen Manuskripte war zudem auf das mangelnde sowjetische Interesse zurückzuführen. Ein am 18. Februar 1945 dem OMI vorgelegter Maßnahmenplan der KPD bemängelte: „Da sich ergeben hat, daß Genosse Korotkewitsch /Verlag für fremdsprachige Literatur] in mehreren Monaten nicht die Zeit hatte, seine Meinung über die vorliegenden Manuskripte auszuarbeiten, schlagen wir vor zu bestimmen, welcher Genosse innerhalb einer Woche die Broschüren druckfertig macht. Wir halten es für notwendig, daß die Arbeitsgruppen, die in das deutsche besetzte Gebiet fah-

sammen mit Emendörfer, Lenski, Lattmann, Schröder und Ulbricht in der „Kulturkommission"; Beschlußprotokolle des Instituts 99 vom 14. 8. und 9. 10. 1944, RGASPI 495/77/46, Bl. 13 und Bl. 25.

87 Emendörfer, Rückkehr an die Front, S. 256 f.

88 Rücker, Die Arbeit der Lehrer im Nationalkomitee, S. 375.

89 Ebenda, S. 373 ff.; vgl. Uhlig, Rückkehr aus der Sowjetunion, S. 57 ff.; „Entwurf eines Lehrplans zur Schulung antifaschistischer Volksschullehrer" vom 15.3. 1945, in: Laschitza, Kämpferische Demokratie, S. $242 \mathrm{ff}$.

90 Hadermann war in der deutschen Zentralverwaltung für Volksbildung, Rücker war von 1946-50 Volksbildungsminister in Brandenburg; Berthold, Die Ausarbeitung von „Richtlinien für den Unterricht in deutscher Geschichte", S. 495 und S. 506.

91 Beschlußprotokoll des Instituts 99 vom 11. 9. 1944, RGASPI 495/77/46, BI. 19; zu Herrnstadt siehe Müller-Enbergs, Der Fall Rudolf Herrnstadt, S. 53.

92 Beschlußprotokoll des Instituts 99 vom 9. 10. 1944, RGASPI 495/77/46, B1. 26. Kügelgens Memoiren (Die Nacht der Entscheidung, S. 469f.) bleiben in dieser Frage offen. Mayenburg (Blaues Blut und rote Fahnen, S. 345) dagegen berichtet von kriegsgefangenen Redakteuren, die im Institut 99 frei ein und aus gegangen seien. 
ren, Broschüren mitnehmen. "93 Pieck erinnerte damit an seinen Vorschlag vom Juli 1944, daß die von Moskau aus eingesetzten Kader zur „Vorbereitung der ideologischen Umerziehung des deutschen Volkes" Informations- und Aufklärungsmaterial mitnehmen sollten. Damals schon verwies er darauf, daß mit der Ausarbeitung bereits begonnen worden sei, womit er vermutlich die Tätigkeit der Übersetzergruppe meinte ${ }^{94}$. Aber erst nach Kriegsende, am 15. Mai 1945, einigten sich Pieck und Kozlov darauf, die Manuskripte von sechs Broschüren - ehedem waren 90 Bände geplant gewesen - bis zum 19. Mai fertigzustellen. Der „Broschüren-Sektor“ im Institut 99 wurde zum 21. Mai 1945 eingestellt ${ }^{95}$. Als Ulbricht Anfang Juni 1945 im OMI den Mangel an "antifaschistischer Literatur" in Deutschland ansprach, verwies Dimitrov auf das Vorhandensein einer "polygraphischen Basis"96. Damit könnten die im Mai vereinbarten Manuskripte gemeint gewesen sein, die aber nicht gedruckt worden waren.

Aus den wenigen Anhaltspunkten zur Tätigkeit der Kommissionen des Nationalkomitees ist erkennbar, daß ihnen erst nach der Entscheidungssitzung im OMI vom 28. November 1944 eine Funktion zugedacht wurde. Nachdem das „Programm des Blockes der kämpferischen Demokratie" vom OMI abgelehnt worden war, diente die darauf folgende zweite Arbeitsphase der KPD-Kommission offensichtlich dazu, deren Ausarbeitungen mit den Ergebnissen aus den NKFD-Kommissionen zusammenzuführen. Den Sitzungen über "Rassentheorie des Hitlerfaschismus" (am 4. und 8. Januar) folgten die Auseinandersetzung mit „Fragen des reaktionären Preußentums" (am 22. Januar und 5. Februar) und schließlich - die Schulbuchkommission des NKFD hatte ihren Entwurf bereits vorgelegt - die Diskussion von „Richtlinien für die Gestaltung des Geschichtsunterrichts in den deutschen Schulen" (am 22. und 26. März)97. Die Kommissionen des NKFD dienten nun als Regulativ zu den Ausarbeitungen der KPD, wobei aufgrund der personellen Verflechtungen die gegenseitige Einflußnahme kaum auseinanderzuhalten ist. Laschitza urteilt, daß sich die Kommissionen von KPD und NKFD in ihrer Arbeit „wechselseitig fruchtbar gestalteten“98. Deutlich legt das Uhlig für den Kulturbereich dar. Die Vorlage zur Planung der Schulpolitik stammte von Edwin Hoernle, der professionelle pädagogische Sachverstand aber kam aus den Reihen der Schulbuchkommission des NKFD ${ }^{99}$. Die Unterrichtsrichtlinien fanden schließlich, ebenso wie der Literaturplan der „Broschüren-Kommission“, Eingang in die "Richtlinien für die Arbeit der deutschen Antifaschisten in dem von der Roten Armee besetzten deutschen Gebiet" vom 5. April 1945100. Diese Richtlinien bildeten somit den inhaltlichen Ersatz des seinerzeit verworfenen „Programms des Blockes der kämpferischen Demokratie“.

93 „Vorschlag für die nächsten Maßnahmen der deutschen Kommunisten“ vom 18. 2. 1945, in: "Gruppe Ulbricht", S. 214.

94 Pieck an Dimitrov am 13. 7. 1944, in: „Gruppe Ulbricht", S. 111.

95 Notizen Piecks „Besprechung mit Koslow am 16. 5. 1945“, SAPMO-BArch NY 4036/500, Bl. 67; vgl. Laschitza, Kämpferische Demokratie, S. 168 ff.

96 Laufer, „Genossen, wie ist das Gesamtbild?“, S. 371.

97 Laschitza, Kämpferische Demokratie, S. $160 \mathrm{ff}$.

98 Ebenda, S. 175.

99 Uhlig, Rückkehr aus der Sowjetunion, S. 58, Anm. 206.

100 „Nach Hitler kommen wir", S. 382 und S. 385. 
Anfang 1945 standen OMI und Institut 99 ohne Alternative zu den Planungen der KPD-Arbeitskommission da. Diese mußte in aller Eile durch die parallel arbeitenden Gremien von NKFD und KPD erst geschaffen werden. Abermals mußte das Institut 99 seiner Koordinierungsfunktion gerecht werden. Ende Januar 1945 beschloß der Zivilsektor, die verantwortlichen Politfunktionäre zusammen zu holen, um die „zukünftigen Aufgaben“ der „Erziehungsarbeit“ abzusprechen ${ }^{101}$. Wie beschlossen, kam es am 5. Februar zu dem Koordinierungstreffen im Institut 99. Pieck fertigte zu dieser Beratung eine längere Notiz an, was darauf schließen läßt, daß es eine ausgiebige Diskussion gab. Anfangs ging es um die Frage der weiteren Einbindung der Offiziere und Generäle des BDO in die Arbeit des Nationalkomitees („Ideologische Arbeit unter Antifaschisten“). Im Generalslager ruhte seit zwei Wochen die innere Schulung, und von einzelnen Generälen (Lattmann, Paulus) kamen Proteste, weil sie nicht in die laufende Arbeit eingebunden worden waren. Mit Blick auf die Jaltaer Konferenz stellte Ulbricht jedoch fest, daß man, solange alliierte Absprachen noch nicht getroffen seien, nicht über die weitere Beteiligung der Generäle an der zukünftigen Arbeit des NKFD entscheiden könne ${ }^{102}$. Ackermann konstatierte einen "Wendepunkt" in der Arbeit des NKFD/BDO, da das deutsche Volk nicht zum erfolgreichen Widerstand gegen Hitler fähig gewesen sei. Er fügte gleich hinzu: „Schuld tragen die deutschen Generäle, konnten sich nicht von Hitler trennen“. Als Konsequenz daraus folgerte er, daß eine „Krise im Nationalkomitee" unvermeidlich sei. Jetzt seien diejenigen gefragt, die für einen Umschwung seien ${ }^{103}$. Braginskij schließlich stellte klar, daß sich die außenpolitische Situation der Sowjetunion "wesentlich geändert" habe. Zu der Frage der anstehenden „Umwälzung“ stellte er jedoch nur fest, daß „Frieden und Freundschaft [zur Sowjetunion]“ zwei Grundbedingungen seien. Als Orientierung für die weitere Deutschlandplanung war das kaum ausreichend. Der abschließende Passus in den Pieck-Notizen zu der Aussprache im Institut 99 läßt zumindest auf eine Desorientierung der KPD schließen: „Wir haben vielfach die Resultate unserer Arbeit überschätzt. Die Situation hat sich wesentlich geändert - Außenpolitik der SU. Die Lage in Deutschland ist schwer - Umwälzung - Was liegt im Interesse des deutschen Volkes? - Frieden und Freundschaft. Ob Großindustrie - Kleinindustrie? Retten,

101 „In der nächsten Zeit soll eine Sitzung der Zivilisten des Nationalkomitees stattfinden, die sich mit den neuen Aufgaben beschäftigen wird“, Beschlußprotokoll des Instituts 99 vom 29. 1. 1945, RGASPI 17/128/788, Bl. 12; vgl. Notizen Piecks „Büro Nationalkomitee 29. 1. 1945“, SAPMO-BArch NY 4036/575, Bl. 258.

102 „Solange nicht Konferenz der drei Großmächte abgeschlossen, keine Aussprache möglich“, Notizen Piecks „Büro NK [Nationalkomitee]- 5. 2. 1945“, SAPMO-BArch NY 4036/575, Bl. 259.

103 Ebenda, Bl. 260: „Ackermann - Wendepunkt - an Arbeit im NK und BDO; Manifest neue Lage - deutsches Volk hat Chance nicht ausgenutzt - Schuld tragen die deutschen Generäle, konnten sich nicht von Hitler trennen. Die Losung, durch den Sturz Hitlers einen besseren Frieden, ist überholt. Eine Krise im Nationalkomitee ist unvermeidlich, weil Generäle nicht mehr gleiche Rolle in der Propaganda spielen wie vorher - mehr im Vordergrund - die ehrlich für einen Umschwung sind." Vor dem Hintergrund der „ideologisch-politischen“ Vorbereitungen, die zu dieser Zeit durch das Institut 99 initiiert wurden, kann angenommen werden, daß sich dieser von Ackermann angesprochene Umschwung auf eine radikale $\mathrm{Ab}$ kehr vom nationalsozialistischen Gedankengut bezog und weniger auf eine Umwälzung des politischen Systems in Deutschland. 
was $\mathrm{zu}$ retten ist, was ist das, was gerettet werden soll? - Wehrmacht nicht nötig. Reaktionäres Preußentum. Was wird am Ende sein? Für Deutschland? - Mit Dimitrov besprechen." 104

Am 6. Februar 1945, zwei Tage nach Beginn der alliierten Konferenz von Jalta, machte Dimitrov den deutschen Kommunisten die für die Deutschlandplanung vollkommen veränderte Lage klar. Es gehe nicht mehr um die Niederringung des nationalsozialistischen Regimes, sondern ausschließlich nur noch um die Formen der Besetzung Deutschlands. Das Nationalkomitee, das vom OMI als Synonym für ein souveränes Deutschland betrachtet worden war, solle seine Propaganda einschränken. Als „Ausführungen von D.“ notierte sich Pieck: „Jetzt nicht Kurs auf neue Regierung. Deutschland wird militärisch besetzt und ökonomisch entwaffnet werden."105 Mit dieser Anweisung Dimitrovs waren die von der KPD noch am 1. Februar 1945 vorgelegten Richtlinien obsolet geworden, die von der Organisierung eines Volksaufstandes im Namen der Bewegung Freies Deutschland und zur Unterstützung der Roten Armee ausgegangen waren ${ }^{106}$. Ebensowenig interessierten die Ergebnisse der gerade wieder in den Kommissionen von KPD und NKFD aufgenommenen Planungsarbeit. Noch am Vortag hatte sich Pieck in Vorbereitung auf das Treffen mit Dimitrov einen Bericht über die „Vorarbeiten für den ideologischen Kampf zur moralisch-politischen Vernichtung des Nazismus“ zurechtgelegt. Er hatte vier Themengebiete notiert, die bearbeitet worden seien: „Rassenfrage“, „Reaktionäres Preußentum“, „Geschichtsfälschungen der Nazis“ und „Schulbildung im neuen Deutschland“. Es seien "Lehrerzusammenkünfte“ in den AntifaSchulen und dem Offizierslager Nr. 150 abgehalten und „provisorische antifaschistische Lehrbücher“ erstellt worden. Als weitere Punkte hatte er „Übersetzungen aus dem Russischen" sowie Ausarbeitungen zur Literatur, zum Theater und zum Kino, die in der Kulturkommission der KPD besprochen worden seien, festgehalten ${ }^{107}$. Im Mittelpunkt der Zusammenkunft aber standen nicht inhaltliche Planungen, sondern der Einsatz der vom Institut 99 seit Monaten geschulten Emigranten und Kriegsgefangenen. Als „Anweisungen von D. “ hieß es in dem Notat Piecks von der Sitzung am 6. Februar im OMI: „Einsetzen von Kadern (vorbereiten); mit Front in Ostpreußen, Brandenburg, Schlesien; im Kontakt mit Rote Armee. Absolut feste, zuverlässige Genossen, die dort Arbeit als Kommunisten leisten. Verbindung mit dortigen Kommunisten herstellen. Erst Regime der Roten Armee, dann Volksausschüsse."108 Dem OMI ging es nun ausschließlich um die personelle Unterstützung des sowjetischen Besatzungsregimes in Deutschland durch die Kader des Instituts 99. Um inhaltliche Planungen von KPD oder NKFD ging es nicht.

104 Ebenda.

105 Notizen Piecks „Ausführungen von D. am 6. 2. 1945“, in: „Gruppe Ulbricht“, S. 183.

106 „Richtlinien für die Propaganda in Deutschland" vom 1. 2. 1945, ebenda, S. $169 \mathrm{ff}$.

107 Notizen Piecks „Besprechung mit D. am 6. 2. 1945“, ebenda, S. 181.

108 Notizen Piecks „Ausführungen von D. am 6. 2. 1945“, ebenda, S. 182. 


\section{3. „Initiativgruppen“}

Den ersten konkreten Plan für den Einsatz vorbereiteter Kader in Deutschland entwarf das OMI, während die Alliierten in Jalta über die Einzelheiten des Besatzungsregimes verhandelten. Nachdem Dimitrov der KPD die entsprechende Anweisung gegeben hatte, wurde noch am 6. Februar von einem Vertreter des OMI (Chvostov) und dem Leiter des Ausbildungscamps in Nagornoe (Guljaev) ein Einsatzplan für die dem Institut 99 zur Verfügung stehenden Kader ausgearbeitet. Die Absolventen der Schule Nr. 12 (1. Kurs), wurden für „Kommandierungen“ in das gesamte Reichsgebiet vorgesehen. Sie sollten ungeachtet der zukünftigen alliierten Besatzungszonen in die Regionen Bremen, Schlesien, Leipzig, Chemnitz, Ruhrgebiet/ Rheinland, Südwestdeutschland und Bayern entsandt werden. Der einzige derartige Einsatz blieb jedoch der von Fritz Krenkel, der am 16. März 1945 mit dem Fallschirm im Erzgebirge abgesetzt wurde ${ }^{109}$. In dem von der Roten Armee okkupierten Gebiet - der zukünftigen sowjetischen Besatzungszone - dagegen sollten „politische Arbeitsgruppen" eingesetzt werden. Diese wurden aus den im Abendkurs und im „engeren Zirkel“ geschulten Kommunisten rekrutiert. Geplant war je eine Gruppe im Bereich der 1. Belorussischen Front („Berlin-Brandenburg“), der 1. Ukrainischen Front („Schlesien-Lausitz und eventuell Sachsen“) und der 2. Belorussischen Front („Pommern und Mecklenburg“). Drittens wurde die Schulung weiterer Kader vorgeschlagen. Dafür sollte das Institut 99 zuverlässige und fachlich qualifizierte Kriegsgefangene in einem speziellen, auf einen anschließenden Einsatz in Deutschland ausgerichteten Antifa-Kurs ausbilden. Zudem sollten 35 der außerhalb Moskaus, d.h. über die sowjetischen Republiken verteilt lebenden Politemigranten in einer einmonatigen Schulung auf die Rückkehr vorbereitet werden. Darüber hinaus sollten alle KPD-Mitglieder, die sich im Exil außerhalb der Sowjetunion befanden, auf eine mögliche Verwendung hin geprüft werden ${ }^{110}$.

Es stand damit ein altes Problem zum wiederholten Male zur Debatte, wie nämlich die Kaderbasis durch das Hinzuziehen derjenigen KPD-Mitglieder, die bislang nicht in die Aktivitäten des OMI einbezogen worden waren, erweitert werden könne. Pieck reichte am 16. Februar 1945 eine Liste mit 79 Namen von Parteimitgliedern ein - doppelt so viel wie vom OMI vorgesehen -, die er für eine Schulung vorschlug: „Die Teilnehmer des Kurses sind in der Regel alte Parteimitglieder, die längere Zeit bereits in der SU als Emigranten leben, jedoch in den letzten Jahren ohne Verbindung mit der Parteiorganisation waren. Ein Teil von ihnen war als Politinstrukteure in Kriegsgefangenenlagern tätig. Der Kursus muß daher im wesentlichen darauf konzentriert sein, die Genossen vor ihrer Abreise nach Deutschland mit der Politik der Sowjetunion vertraut zu machen."111 Die am

${ }_{109}$ Ebenda, S. 187, Anm. 1.

110 „Vereinbarung von Vorschlägen auf der Sitzung vom 6. Februar mit Genossen Chwostow und Guljajew", ebenda, S. $185 \mathrm{f}$.

111 Einleitung zum „Lehrplan für den Monatskurs in Nagornoje“, Anlage zum Brief Piecks an Dimitrov vom 16. 2. 1945, SAPMO-BArch NY 4036/531, Bl. 92-96. Der Kurs war auf 20 Lektionen angelegt, die theoretischen Themen (Imperialismus/Faschismus), die Politik der KPD seit dem Ersten Weltkrieg und den „historischen Sieg des Sowjetvolkes über den deutschen Imperialismus" sowie die daraus folgenden Aufgaben der deutschen Kommunisten abhandelten. 
30. April als „erneute Abschrift“ abermals eingereichte Liste - beim zweiten Mal wurde eine Auswahl von 32 Kommunisten vorgeschlagen - zeigt jedoch, daß bis dahin seitens des OMI nichts unternommen worden war. Auch der dritte Vorschlag vom 31. Mai führte nicht zur der von der KPD gewünschten Schulung. Der „Monatskurs" fand nie statt ${ }^{112}$.

Die Kaderbasis blieb trotz konkreter Vorschläge schmal. Der Grund dafür wird darin zu suchen sein, daß die Kaderrekrutierung ausschließlich über das Institut 99 lief. Auseinandersetzungen mit dem UPVI, das zahlreiche der für den Monatskurs vorgeschlagenen Kommunisten als Politinstrukteure beschäftigte, aber wollte das Institut 99 aus dem Weg gehen. Es wäre ihnen wohl auch nicht gewachsen gewesen. So wurde ein Teil der für den Monatskurs vorgeschlagenen KPD-Mitglieder aus der Provinz im dritten und vierten Kurs an der Schule Nr. 12 geschult ${ }^{113}$. Ebenso gab es Beschränkungen bei der Rekrutierung antifaschistisch geschulter Kriegsgefangener über die Fronten der Roten Armee. Die antifaschistischen Frontschulen unterstanden der 7. Verwaltungen des GlavPURKKA und wurden somit nie in die Planungen des Instituts 99 bzw. des OMI einbezogen. War dieser Umstand bereits im Zusammenhang mit der Frontpropaganda des NKFD deutlich geworden, so stellte Pieck in der "Leitungssitzung" der KPD-Führung am 17. Februar 1945 diese Zuständigkeiten nochmals klar: „Mitarbeit von Kriegsgefangenen beim Einsatz: 1) Auswahl durch Pur [GlavPURKKA] aus den in der Frontarbeit der Pur bewährten Antifaschisten, 2) Auswahl durch Kaderabteilung Institut 99."114 Eingedenk dieser Möglichkeiten hieß es in den am 18. Februar 1945 vorgelegten Richtlinien über Auswahl und Einsatz von Kadern: „Wir schlagen vor, die Kaderabteilung beim Institut 99 zu beauftragen, folgende Kriegsgefangene zu prüfen und die Geeigneten für die Arbeit im besetzten Gebiet auszuwählen: a) die bisherigen Frontbeauftragten des Nationalkomitees und Armeebeauftragten, die nicht mehr von der Roten Armee direkt verwendet werden; b) die Schüler des gegenwärtigen Lehrganges der Schule 27 [Krasnogorsk] und der Schule 165 [Juža] sowie die Schüler, die sich als Reserve im Lager 27, Zone 3, befinden und die Antifaschisten auszuwählen, die für die Arbeit im sowjetisch besetzten deutschen Gebiet geeignet sind; c) Auswahl der zuverlässigen Antifaschisten aus den Reihen des Nationalkomitees und seiner Mitarbeiter im Haus Nr. 15 [Lager Lunevo] (...); d) Auswahl von 100 der besten antifaschistischen Kriegsgefangenen aus den Arbeitslagern, die eine gewisse Vorschulung haben und die sich im ideologischen Kampf und in der Produktionsarbeit bewährt haben; e) Auswahl von 100 Intellektuellen, die antifaschistisch gesinnt sind (Lehrer, Ärzte, Ingenieure und dergleichen aus den Offizierslagern); f) Auswahl einer Anzahl antifaschistischer Geistlicher der evangelischen und katholischen Kirche."115

112 Es handelte sich immer um denselben Personenkreis, der zwei- bzw. dreimal vorgeschlagen wurde, Teilnehmerlisten vom 16. 2. 1945 (79 Personen), 30. 4. 1945 (32 Personen) und 31. 5. 1945 (40 Personen), SAPMO-BArch NY 4036/531, B1. 97-107; ebenda Bl. 91 der Vermerk „KPD Monatskurs in Nagornoje, Mai 1945, hat nicht stattgefunden“.

113 Albert Baum, Erwin Born, Sali Glogowsky, Hermann Lask, und Heinrich Wieland (3. Kurs), Jonny Dietrich, Hans Kahlmüller und Käthe Stange (4. Kurs); vgl. SAPMOBArch NY 4036/532, Bl. 97-107, siehe Anlage Nr. 2.

114 Notizen Piecks „Besprechung der Leitung am 17. 2. 1945“, in: „Gruppe Ulbricht“, S. 203.

115 „Vorschlag für die nächsten Maßnahmen der deutschen Kommunisten“ vom 18.2. 1945, cbenda, S. $213 \mathrm{f}$. 
Der Kreis der dem Institut 99 zur Verfügung stehenden und der potentiell auszuwählenden Kader war am 18. Februar festgelegt. Nun ging es darum, die Aufgaben der Einsatzgruppen festzulegen, wobei es zu langwierigen Abstimmungsschwierigkeiten zwischen OMI und KPD kam. Nachdem zu Jahresbeginn eine Überarbeitung des „Blockes der kämpferischen Demokratie“ angeordnet, im weiteren im OMI aber über deutschlandpolitische Konzepte nicht mehr geredet worden war, waren sich die deutschen Kommunisten nicht im klaren über die zukünftige sowjetische Besatzungspolitik. Nach ihren Vorstellungen sollten die in Deutschland einzusetzenden Kader Volksausschüsse gründen, die die spätere Basis für den Aufbau einer Parteiorganisation bilden würden. Aber das waren die Ideen der KPD. Pieck erkundigte sich am 15. Februar vorsichtshalber bei Dimitrov: „Welche Konsequenzen ergeben sich aus den Beschlüssen der Krim-Konferenz: a) im öffentlichen Auftreten des Nationalkomitees Freies Deutschland und unserer Genossen, die Mitglieder des Nationalkomitees sind? b) Ist es möglich, in den von der Roten Armee besetzten Gebieten neben den im Aufruf des Berliner Volksausschusses und in den Richtlinien [vom 1. Februar 1945] gestellten Aufgaben auch die Radio-, Flugblattund Zeitungspropaganda der Bewegung ,Freies Deutschland' nach den hitlerdeutschen Gebieten zu entfalten und die entsprechenden Maßnahmen mit Unterstützung der Roten Armee durchzuführen? c) Gibt es schon Beschlüsse über die von der Roten Armee in den besetzten Gebieten zu treffenden Maßnahmen und wie soll die von den Parteigruppen durchzuführende Arbeit eingegliedert werden?" $116 \mathrm{Da}$ es auch nach Abschluß der Jaltaer Konferenz noch keine konkreten Vorgaben für die Errichtung einer sowjetischen Besatzungsverwaltung in Deutschland gab, gingen die deutschen Kommunisten vorerst von ihren bisherigen Planungen aus. Noch auf der am 17. Februar abgehaltenen „Leitungssitzung“ rechnete die KPD-Spitze mit der „Entfaltung einer breiten Massenbewegung zur Bildung von lokalen und gebietl[ichen] Volksausschüssen, die sich stützen auf die Bewegung ,Freies Deutschland' als der breitesten Zusammenfassung aller fortschrittl[ichen] demokratischen, antinazistischen Kräfte, wobei wir die feste Arbeiter-Einheitsfront der komm[unistischen], sozial[demokratischen] und gewerkschaftlich org[anisierten] Arbeiter erstreben."117

Das OMI präzisierte seine deutschlandpolitischen Vorstellungen erst am Abend des 17. Februar. Dimitrovs Stellvertreter Panjuškin erläuterte Pieck, Ulbricht und Ackermann das geplante Vorgehen: Zuerst müsse die Lage in Deutschland erkundet, dann darüber in Moskau berichtet, und danach erst könne über den Aufbau der KPD, die Schaffung von Volksausschüssen und die Herausgabe von Zeitungen entschieden werden. Den sofortigen Aufbau von Partei und Gewerkschaften lehnte das OMI eindeutig ab: „Über Schaffung von Gewerkschaften und Parteiorganisation noch keine Direktive." Auf der anderen Seite wurde die „Linie des Nationalkomitees" faktisch für beendet erklärt. Auf keinen Fall, so betonte Panjuškin, würden die

116 Pieck an Dimitrov am 15. 2. 1945, in: „Gruppe Ulbricht“, S. 191; in der Anlage „Entwurf zu Anweisungen für die Anfangsmaßnahmen zum Aufbau der Parteiorganisation in den besetzten Gebieten", ebenda, S. $194 \mathrm{ff}$.

117 Ebenda, S. 200; siehe auch die Überlegungen der KPD zum Aufbau der Partei und von Massenorganisationen in den von der Roten Armee besetzten Gebieten (ebenda, S. $202 \mathrm{f}$.), die bereits dem Schreiben an Dimitrov vom 15.2. 1945 als Anlage beigefügt worden waren, ebenda S. 194. 
Volksausschüsse eine Fortsetzung des Nationalkomitees sein. Das Nationalkomitee solle nur deswegen weiterarbeiten, „weil zur Zersetzung des Offizierskorps wichtig" und weil darüber benötigte Kader wie Lehrer und Geistliche rekrutiert werden könnten („Pfarrer ausnutzen zu Ausrottung des Nazismus und Militarismus“)118. Nach den Ausführungen Panjuškins sollte der Kadereinsatz in Deutschland lediglich die organisatorischen Voraussetzungen schaffen, um dann in einer zweiten Phase diejenigen Aufgaben zu erfüllen, die Mitte Februar vom OMI noch gar nicht klar definiert wurden. Zuerst würden Volksausschüsse geschaffen, dann deren Aufgaben festgelegt werden. Gemäß dieser Vorgaben überarbeitete die KPD ihre Richtlinien vom 1. Februar, die nie Grundlage einer Diskussion geworden waren, und legte am 18. Februar eine Neufassung vor. Nun wurde in "Vorbereitungen“ und „weitere Aufgaben“ unterschieden. Danach sollte der erste Kadereinsatz dazu dienen, in Deutschland kommunistische Funktionäre ausfindig zu machen und den „organisatorisch-ideologischen Zustand sozialdemokratischer, christlicher und bürgerlicher Gruppierungen“ zu prüfen, um für die „weitere Arbeit“ wie den Aufbau der KPD, der Gründung von Volksausschüssen und der Schaffung von Massenorganisationen gewappnet zu sein ${ }^{119}$.

Von dem Konzept der Volksausschüsse rückte das OMI zwei Tage später ab. Die von der KPD gerade erst fixierte Aufgabenbeschreibung für den Kadereinsatz in Deutschland entsprach somit abermals nicht den sowjetischen Vorstellungen. Am 19. Februar folgte eine weitere Besprechung im OMI. Dimitrov konkretisierte die kommenden Aufgaben: Es seien "Gruppen zur Unterstützung der Roten Armee" $\mathrm{zu}$ bilden, die zusammengesetzt würden aus kommunistischen Remigranten und Kriegsgefangenen aus der Sowjetunion sowie Kommunisten und Antifaschisten aus der Ortsbevölkerung in den besetzten Gebieten. An der Spitze dieser - wie es nun hieß - "provisorischen Ortskommissionen" sollten "geprüfte Kommunisten" stehen. Von Volksausschüssen war nicht mehr die Rede. Pieck übermittelte der KPDSpitze Dimitrovs Anweisungen, wobei er ausdrücklich betonte: „Provisorische deutsche Ortskommissionen (nicht Volksausschüsse), eingesetzt von Armeekommandos, bestehend aus überprüften Kommunisten und Antifaschisten; Aufgaben Hilfe erweisen im Leben der Gemeinden. Volksausschüsse erst später." 120 Der am 20. Februar erneut von der KPD vorgelegte Aufgabenplan für die einzusetzenden Kader sprach nun von der „Mithilfe bei der Schaffung provisorischer Ortskommissionen". Im Unterschied zur ursprünglichen, mit Chvostov und Guljaev erarbeiteten Vorlage für den Kadereinsatz war auch nicht mehr von „Kommandierungen“ in das gesamte Reichsgebiet, sondern lediglich vom Einsatz vier- bis fünfköpfiger Gruppen von KPD-Mitgliedern „zur Unterstützung der Roten Armee in den von ihr besetzten deutschen Gebieten“ die Rede ${ }^{121}$. Erst später, „sobald die Vorausset-

118 Notizen Piecks über die „Besprechung bei Panuschkin ZK“ am 17. 2. 1944, ebenda, S. 206. 119 „Übersicht über die Aufgaben“ vom 18. 2. 1945, ebenda, S. $216 \mathrm{ff}$.; vgl. „Richtlinien für die Propaganda in Deutschland" vom 1.2.1945, ebenda, S. $169 \mathrm{ff}$.

120 Notizen Piecks „Besprechung bei Dimitrov am 19. 2. 1945“ und „Besprechung am 19. 2. 1945“, ebenda, S. 228 ff.; zur Zuordnung der Notizen siehe ebenda, Anm. 1, S. 233.

121 Gustav Sobottka, Richard Gyptner, Fritz Appelt und Käthe Wald an die 1. Ukrainische Front, Otto Winzer, Stanislaw Switalla, Wolfgang Leonhard, Margarete Keilson und Selma Gabelin an die 1. Belorussische Front und Hermann Matern, Fritz Kahmann, Heinz Abraham und Ernst Noffke an die 2. Belorussische Front. 
zungen gegeben sind“, sollten Redaktionsstäbe für Zeitungen und Radiostationen sowie eine Gruppe unter Leitung des Auslandsbüros der KPD (Walter Ulbricht und Anton Ackermann) folgen. Diese sollte vermutlich den Aufbau des Parteiapparates in Angriff nehmen ${ }^{122}$.

Die Planungen im OMI kamen am 20. Februar zu einem Ende. Aber erst einen Monat später, am 19. März, entschied die sowjetische Führung über das Vorgehen in Deutschland. Dimitrov sprach bei Stalin vor ${ }^{123}$. Dem Gespräch folgte ein Bericht, in dem die Absprachen mit der KPD von Mitte Februar 1945 zusammenfaßt und das zukünftige Verhältnis zum NKFD - nach außen immer noch die tragende Säule der sowjetischen Propaganda - klargestellt wurde. Das OMI benannte drei Aufgabenfelder: die Propaganda, die Zusammenarbeit mit „deutschen Antifaschisten“ und die Vorbereitung von Kadern für den Einsatz in Deutschland. Unter Propaganda wurde die politische Aufklärung über Zeitung und Rundfunk sowohl von Seiten der Roten Armee als auch von Seiten "deutscher Antifaschisten" verstanden. Es war damit nicht die Frontpropaganda des NKFD gemeint. Das Nationalkomitee wurde von allen weiteren, die sowjetische Besatzungspolitik betreffenden Planungen ausgenommen. Seine Propaganda sollte nur noch für das Gebiet gelten, das nicht von der Roten Armee besetzt werden würde. Die Verwaltung des sowjetischen Besatzungsgebietes aber sollte in Zusammenarbeit mit „Antifaschisten (Mitgliedern der Kommunistischen Partei und anderen)" als "vorläufige Hilfsorgane“ erfolgen. Als Aufgaben dieser Hilfsorgane wurden genannt: „Unterstützung der sowjetischen Militärbehörden beim Aufspüren von versteckten Faschisten und bei der Verhinderung von Sabotage; Hilfe bei der Organisierung der kommunalen Versorgung, beim Bau und der Reparatur von Straßen, bei der Mobilisierung der Bevölkerung; Hilfe bei der Einrichtung von Gerichten für kleinere Zivilangelegenheiten, des Schul- und Bibliothekswesens, der Versorgung, insbesondere beim Ausfindigmachen von Nahrungsmittelvorräten wie auch Vermögen, das der Beschlagnahme unterliegt. Die Hilfsorgane unterstützen beim Ausfindigmachen und Überprüfen von Kommunisten und anderen Antifaschisten aus den Reihen der örtlichen Bevölkerung." 124

Die dritte vom OMI benannte Aufgabe betraf die Rekrutierung zuverlässiger Kader durch das Institut 99, wie sie seit dem Sommer 1944 immer wieder diskutiert worden war. Zur Vorbereitung neuer Lehrer für deutsche Schulen sollte in der Antifa-Schule Krasnogorsk ein zweimonatiger Kurs mit 300 Kriegsgefangenen, die durch ihren Zivilberuf eine entsprechende pädagogische Ausbildung hatten, durchgeführt werden. In diesem Zusammenhang wurde auch an die Vorbereitung neuer Schulbücher - an denen das Institut 99 seit knapp einem Jahr arbeitete - erinnert. Außer Lehrern sollten ,antifaschistisch eingestellte Intellektuelle und sonstige Spezialisten“, insbesondere Ärzte in einem für 100 Teilnehmer geplanten Antifa-Kurs in Krasnogorsk geschult werden. Ferner wollte man 30-40 Geistliche - offensichtlich die Aktivisten aus dem Arbeitskreis des NKFD für kirchliche Fragen - in einem

122 „Vorschlag für den Einsatz von Kadern der KPD“ vom 20. 2. 1945, in: „Gruppe Ulbricht“, S. 234.

123 Posetiteli kremloskogo kabineta, S. 95.

124 Dimitrov und Panjuškin an Molotov und Malenkov im März 1945, in: Sowjetische Politik in der SBZ, S. $5 \mathrm{f}$. 
Lager zusammenlegen und mit ihnen die „entsprechende Arbeit“ durchführen, d.h. sie politisch schulen ${ }^{125}$.

Anfang April kam die Bestätigung der vom OMI gemachten Vorschläge zu Auswahl und Einsatz deutscher Kader. Dimitrov bestellte die KPD-Spitze zu sich und legte den Beschluß der sowjetischen Führung dar. Inhaltlich wich er nicht von den im Februar erarbeiteten Konzepten ab, jedoch hieß es nun, daß die für den Einsatz vorgesehenen 30 Kriegsgefangenen - Absolventen der Schule Nr. 12 - „viel zu wenig" seien. Dimitrov verlangte weitere Kadervorschläge und lockerte zugleich die Auswahlkriterien. So sei die Mitgliedschaft in der NSDAP kein Hindernis für den Einsatz, sofern der Kriegsgefangene sich als Aktivist bewährt habe. Diese Anweisung bezog sich ganz offensichtlich auf die Rekrutierung von Offizieren, von denen vor allem die Reserveoffiziere zu dem vom OMI gewünschten Kreis der „intellektuellen Spezialisten “ wie Lehrer, Ärzte und Ingenieure zählten ${ }^{126}$. Das Institut 99 prüfte daraufhin die Mitglieder des NKFD im Lager Lunevo auf ihre mögliche Verwendung in Deutschland. Das Ergebnis entsprach nur zum Teil den Erwartungen. Eine Aufschlüsselung nach Berufen ergab, daß von 61 erfaßten NKFD-Mitgliedern 24 Berufsoffiziere waren. Berufssoldaten aber, die keine zivile Berufsausbildung besaßen, entsprachen nicht der Kategorie der „intellektuellen Spezialisten“. Zudem setzte das OMI Anfang Juni fest, daß keine kriegsgefangenen Generäle eingesetzt würden 127 . Die Spitze des BDO war damit von einem Einsatz in Deutschland ausgeschlossen. Somit kamen unter Berücksichtigung der vom OMI gemachten Kriterien von den Aktivisten des BDO/NKFD nur sieben Geistliche, sechs Lehrer, vier Ingenieure, drei Ärzte, sechs Reserveoffiziere aus sonstigen akademischen und neun aus kaufmännischen Berufen, ein Handwerker und ein Bauer in Betracht (37 Personen) ${ }^{128}$.

Für den sofortigen Einsatz in Deutschland wurden insgesamt nur 20 Mitglieder des Nationalkomitees ausgewählt. Kriterium war, daß die Komiteemitglieder sich loyal gegenüber der Sowjetunion verhalten würden. Gradmesser dafür war die Teilnahme an der ,inneren Schulung“ oder der Antifa-Schule129. Ein weiterer Ansatzpunkt, auf den zur Rekrutierung „intellektueller Spezialisten“ zurückgegriffen werden konnte, war die im Herbst 1944 im Offizierslager Grjazovec initiierte „Lehrer-

125 Ebenda, S 6.

126 „Einsatz von kommunistischen und antifaschistischen Kadern im besetzten Gebiet; auf eingereichter Liste nur 30 Antifaschisten, viel zu wenig, keine Begrenzung wegen Zwangsmitgliedschaft in der Nazipartei; neue Liste mit Charakteristiken, auch von Kommunisten", Notizen Piecks von der Besprechung mit Dimitrov am 1.4. 1945, in: "Gruppe Ulbricht", S. 256.

127 „Einsatz von Kadern, bei Kriegsgefangenen bis zum Oberst“, Notizen Piecks vom 4.6. 1945, ebenda, S. 471.

128 Undatierte Liste mit Namen, Dienstgrad, Beruf und eine ebenfalls undatierte "Zusatzliste der außerhalb des Hauses Lunevo befindlichen Vorstandsmitglieder des BDO“, SAPMOBArch NY 4065/19, B1. 1-3; vgl. „Einschätzung und Verwendung der Kriegsgefangenen in Objekt Nr.15" (ohne Datum), die die Berufsoffiziere nicht berücksichtigt, RGVA/K 88/3/1, Bl. 164-179.

129 Unter Berücksichtigung dieser Gesichtspunkte wurden vorgeschlagen: Stößlein, Schröder, Hadermann, Fleischer, Rücker, von Kügelgen, Gerlach, Klement, Helmschrott, Kertzscher, Grandy, Krausnick, Emendörfer, Achilles, Krummacher, Dengler, Abel, Strampfer, von Knobelsdorff und Hartmann; Weinert an Kijatkin, Pieck und Kozlov am 4. 6. 1945, SAPMO-BArch NY 4036/517, Bl. 142-144. 
gruppe“. Deren Erfolge aber waren gering geblieben. Die Anfang April 1945 plötzlich erteilte Anweisung des OMI, die Zahl der einzusetzenden Kader zu erhöhen, entbehrte somit jeglicher Grundlage. Am 3. April 1945 mußte Pieck an Dimitrov berichten: „Auch die Prüfung aller Kriegsgefangenen, die als Kandidaten in Frage kommen, hat die Zahl der Volksschullehrer nicht nennenswert erhöht. Es gibt keinen anderen Ausweg, als aus den Kriegsgefangenenlagern alle geeigneten Lehrer herauszuholen sowie solche intelligente Werktätige, die für die künftige Arbeit als Hilfslehrer geeignet sind. Diese müßten den nächsten Lehrgang der Schule Nr. 27 besuchen und dort die notwendige antifaschistische Grundschulung erhalten."130

Die Vorschläge zur Rekrutierung zusätzlicher Kader wiederholten sich. Pieck schlug für den sofortigen Einsatz die Absolventen der Schule Nr. 12 (49 Personen) und "für leitende Funktionen" diejenigen kommunistischen Funktionäre vor, die das OMI bereits im Februar ausgewählt hatte (47 Personen) $)^{131}$. Außerdem drängte er darauf, den „Monatskurs“ für die kommunistischen Emigranten außerhalb Moskaus endlich zu realisieren. Zudem fügte er eine Liste mit den Namen derjenigen KPD-Mitglieder bei, die sich in westlichen Exilländern befanden ${ }^{132}$. Das OMI aber ging auf die Kadervorschläge der KPD nicht ein. Es konzentrierte sich auf den einmal durch das Institut 99 ausgewählten Kaderstamm. Allerdings entsprach die im Herbst 1944 begonnene Ausbildung nicht mehr den aktuellen Anforderungen, weil die Aufgaben der einzusetzenden Kader auf reine Kommunalverwaltung reduziert worden waren. Für die Absolventen der „Abendschule“ in Moskau wurden daher vom 15. April bis zum 8. Mai 1945 erneut Schulungsabende angesetzt. Nun wurden den Teilnehmern detailliert die kommunalen Verwaltungsaufgaben erklärt ${ }^{133}$. Leonhard, der als Mitarbeiter des Instituts 99 und Nachwuchsfunktionär der KPD daran teilnahm, erinnert sich, daß die Unterstützung der sowjetischen Besatzungstruppen und die Umerziehung des deutschen Volkes im Vordergrund standen. Von einer Neugründung der Parteien, insbesondere der KPD, sei nicht gesprochen worden ${ }^{134}$. Dem entsprachen auch die Richtlinien vom 5. April 1945, die die KPD in Analogie zu den zwischen OMI und sowjetischer Führung beschlossenen Aufgaben für den Kadereinsatz ausgab: „Die auf dem besetzten deutschen Gebiet tätigen Antifaschisten arbeiten in vollem Einvernehmen mit der Besatzungsbehörde und sorgen durch ihre Arbeit unter der Bevölkerung dafür, daß die Befehle und Anweisungen der Besatzungsbehörde als im Interesse des deutschen Volkes liegend unbedingt durchgeführt werden. Die Hauptaufgaben sind: Die Herstellung der Ordnung, Schaffung der Bedingungen des täglichen Lebens der Bevölkerung, Unterstützung der Roten Armee bei der Liquidierung der nazistischen Terror- und Provokationsnester und Organisierung des Kampfes für

130 Pieck an Dimitrov am 3. 4. 1945, in: „Gruppe Ulbricht“, S. 258.

13133 von ihnen waren bereits im Februar vorgeschlagen worden, SAPMO-BArch NY 4036/517, Bl. 116-121. Diese Liste trägt den Kanzleivermerk „24. 2. 1945. Nochmalige Abschrift am 30.4. 1945“. 14 Kader wurden in der "Ergänzungsliste“" (SAPMO-BArch NY 4036/517, Bl. 122-123) neu vorgeschlagen.

132 Pieck an Dimitrov am 3. 4. 1945, in: „Gruppe Ulbricht“, S. 258.

133 Vgl. die von Pieck geführte Anwesenheitsliste und seine Notizen über die Sitzungen am 15. 4., 20. 4., 24. 4., 27. 4., 4. 5. und 8. 5. 1945, ebenda, S. $266 \mathrm{ff}$.

134 Leonhard, Revolution, S. $324 \mathrm{ff}$. Leonhard geht von etwa 150 Teilnehmern aus. Dies läßt sich allerdings auf Grundlage der Quellen nicht belegen. 
die politisch-moralische Ausrottung des Nazismus, Militarismus aus dem Leben des deutschen Volkes." 135

Am 25. April erfolgte die Einweisung der Kader in den unmittelbar bevorstehenden Einsatz. Kurz zuvor (am 20. April) waren die Frontstäbe der Roten Armee per Direktive des sowjetischen Oberkommandos (stavka) über die Bildung deutscher Ortsverwaltungen instruiert worden. In den Stäben waren Abteilungen für die Zivilverwaltung geschaffen worden, über die sowjetische Offiziere in dem besetzten Gebiet als Ortskommandanten eingesetzt wurden ${ }^{136}$. In dieses organisatorische Geflecht integrierte das OMI den Einsatz deutscher Kader aus Moskau. Pieck notierte gewissenhaft Dimitrovs Instruktionen: „Pol/itische] Arbeit nach Anweisung der Pur [GlavPURKKA], wozu von uns Vorschläge, keine eigene Org[anisation] u[nd] Initiative." 137 Am 29. April gab Dimitrov grünes Licht für den Einsatz der ersten drei Gruppen: die „Ulbricht-Gruppe“ am 30. April an der 1. Belorussischen Front, die "Ackermann-Gruppe“ am 2. Mai an der 1. Ukrainischen Front (es wurde der 1. Mai) und an der 2. Belorussischen Front - noch ohne Nennung eines Datums - die "Sobottka-Gruppe“ (es wurde der 6. Mai) ${ }^{138}$. Die nach Deutschland geschickten Gruppen bestanden insgesamt aus 30 Politemigranten und 29 Kriegsgefangenen. Die Emigranten kamen aus dem ehemaligen Kominternapparat. Zwei Drittel von ihnen hatten im Institut 99, fast alle übrigen in den Instituten 100 und 205 gearbeitet. Sie hatten in die Regel die „Abendschule“ im Institut 99 besucht. Absolventen der Schule Nr. 12 aber wurden nicht eingesetzt. Die Kriegsgefangenen waren „bewährte Antifaschisten“, die als Frontpropagandisten gearbeitet hatten, oder als Absolventen der Antifa-Schule aus der "Reserve“ des Instituts 99 kamen ${ }^{139}$.

Beim ersten Einsatz deutscher Kader wurde auf organisationserfahrene Kominternfunktionäre und in der Zusammenarbeit mit der Politischen Hauptverwaltung erprobte Kriegsgefangene zurückgegriffen. Einzige Aufgabe war die Hilfestellung für die Rote Armee bei der Bewältigung kommunaler Versorgungs- und Ordnungsaufgaben. Selbst die in den Richtlinien erwähnte Unterstützung der sowjetischen Besatzungsmacht bei der Entnazifizierung wurde nicht den „deutschen Antifaschisten" überlassen. Dafür hatte das NKVD einen eigenen, umfangreichen Apparat aufgebaut ${ }^{140}$. In Berlin hielt sich Ulbricht strikt an die Vorgabe, lediglich die Stadtverwaltung in Gang zu bringen. Alle weitergehenden politischen Aktivitäten von Kommunisten oder Mitglieder anderer Parteien wurden unterbunden ${ }^{141}$.

Die Bezeichnung der Kadergruppen unter Leitung von Ulbricht, Ackermann und Sobottka als „Initiativgruppen der KPD“ ist daher ein Euphemismus. Die deut-

135 „Richtlinien für die Arbeit der deutschen Antifaschisten in dem von der Roten Armee besetzten deutschen Gebiet" vom 5. 4. 1945, in: „Nach Hitler kommen wir", S. 380.

136 Foitzik, Sowjetische Militäradministration, S. $76 \mathrm{ff}$. und $331 \mathrm{ff}$.

137 Notizen Piecks von der Besprechung bei Dimitrov am 25. 4. 1945, in: „Gruppe Ulbricht“, S. 277.

138 Notizen Piecks von der Besprechung bei Dimitrov am 29. 4. 1945, ebenda, S. 284.

139 Siehe Anlage Nr. 3.

140 Am 18. 4. 1945 ordnete das NKVD die Errichtung von Internierungslagern für NS- und Kricgsverbrecher auf dem Territorium der zukünftigen sowjetischen Besatzungszone an; dazu siehe Possekel, Sowjetische Lagerpolitik in Deutschland, insbes. S. $49 \mathrm{ff}$.

141 Vgl. Ulbricht an Pieck am 9. 5. 1945, in: "Gruppe Ulbricht", S. 318 ff.; siehe auch Creuzberger, Die Liquidierung antifaschistischer Organisationen, S. $1266 \mathrm{ff}$. 
schen Kommunisten mußten sich strikt an die Anweisungen der Roten Armee bzw. an die zuvor vom OMI definierten Aufgaben halten.

\section{Einsatz der Parteischüler}

Die Parteikader, die das Institut 99 in der Schule Nr. 12 ausgebildet hatte, wurden erst eingesetzt, als die Entscheidung darüber gefallen war, die KPD als Partei in der SBZ zuzulassen. Bereits am 29. April war im OMI die Rede davon gewesen, „Aktivistengruppen " in der Stärke von drei bis fünf Personen nach Berlin, Stettin und Dresden - den Einsatzorten der Gruppen Ulbricht, Sobottka und Ackermann - zu schicken, damit sie dort damit beginnen, Verbindungen zu den ehemaligen Parteigruppen in Deutschland aufzubauen. Solange es aber noch keine sowjetische Entscheidung über die Zulassung der KPD gab, hätten diese Gruppen verdeckt arbeiten müssen, was offensichtlich einkalkuliert wurde ${ }^{142}$. In seinem Bericht an das OMI vom 17. Mai drängte Ulbricht auf die Genehmigung zum verdeckten Aufbau einer kommunistischen Parteiorganisation: „Es wird notwendig sein, eine nicht legale provisorische Leitung für Berlin aus fünf Genossen zu schaffen. Wenn unsere Politik richtig durchgeführt werden soll, so müssen wir eine Partei schaffen, die zu Dreiviertel aus neuen Mitgliedern bestehen muß. Auch in eine später zu schaffende Parteileitung müssen wir neue Antifaschisten hineinbringen, wenn auch die alten ZK-Mitglieder in der Minderheit sind." 143

Bei der Mitte Mai beginnenden Zusammenstellung weiterer Kadergruppen zur Unterstützung der ersten drei Gruppen wurden Ulbrichts Vorschläge nur teilweise berücksichtigt. Mit der vierten Gruppe fuhren zwar erstmals Absolventen der Schule Nr. 12 nach Deutschland (33 Kriegsgefangene und 21 Politemigranten), aber ihnen wurden 57 Antifa-Schüler ohne spezielle Parteischulung zur Seite gestellt. Insgesamt wurden somit 90 , nur bedingt auf einen Parteieinsatz vorbereitete Kriegsgefangene und lediglich 21 Politemigranten entsandt ${ }^{144}$. Wie bei den ersten drei Gruppen erhielt Pieck den Hinweis „Abreisende stehen nicht zur Verfügung der KPD - sondern zur Verfügung der R[oten] A/rmee] [und] ihrer Organe“. Aber er notierte sich auch: „Es wird Zeit kommen, wenn KPD als Partei, dann leichter $\mathrm{zu}$ arbeiten." 145 Auch wenn damit ganz offensichtlich die Bewältigung allgemeiner kommunaler Verwaltungsaufgaben nach wie vor im Vordergrund stand, so schufen die nach Deutschland geschickten Absolventen der Parteischule eine erste kaderpolitische Grundlage für den Aufbau der KPD in Deutschland. Die Entscheidung über die Zukunft der KPD fiel sogar noch vor der Abreise der vierten Gruppe am 28. Mai. Zwei Tage zuvor, am 26. Mai, hatte Pieck die Anweisung zur Ausarbeitung eines Gründungsmanifestes der KPD erhalten. Der daraufhin vorgelegte Entwurf wurde auch am 30. Mai im OMI besprochen, allerdings ging es auf dieser Sit-

142 Notizen Piecks von der Besprechung vom 29. 4. 1944, in: „Gruppe Ulbricht“, S. 286.

143 Ulbricht an Dimitrov am 17. 5. 1945, ebenda, S. 354.

144 Siehe Anlage Nr. 3.

145 Notizen Piecks von der Besprechung bei Dimitrov am 25. 5. 1945, in: „Gruppe Ulbricht“, S. 385 f; anwesend waren außerdem Braginskij (7. Verwaltung), Kijatkin (Leiter der AntifaSchule in Juža), Chvostov (Kaderabteilung OMI) und Kozlov (Institut 99). 
zung noch nicht um die tatsächliche Zulassung der KPD in der SBZ, sondern lediglich um die Formulierung eines Aufrufes. Alle von Pieck gestellten Fragen zum konkreten Aufbau der Parteiorganisation blieben unbeantwortet. Darüber wurde erst gesprochen, als Ulbricht, Ackermann und Sobottka Anfang Juni nach Moskau zurückkehrten, um über ihre Eindrücke und Erfahrungen zu berichten ${ }^{146}$.

$\mathrm{Zu}$ den Anfang Juni 1945 in Moskau durchgeführten Gesprächen der deutschen Kommunisten mit der sowjetischen Führung gibt es ein auf den 4. Juni datiertes Notat Wilhelm Piecks, dessen Interpretation jedoch strittig ist ${ }^{147}$. Zusammengefaßt können die Ereignisse folgendermaßen rekonstruiert werden: Ulbricht, Ackermann und Sobottka berichteten direkt nach ihrer Ankunft in Moskau am frühen Abend (,18.45 - 20.30 Uhr") bei Stalin und Molotov ${ }^{148}$. Bei diesem nicht ganz zweistündigen Treffen - über das keine Aufzeichnungen vorliegen - ging es vermutlich nur um einen knappen Bericht über die Lage in Deutschland, bei dem offenbar die Frage der Kontrolle über das besetzte Gebiet im Mittelpunkt stand. Außer den Leitern der deutschen Kadergruppen war nur noch der verantwortliche Bevollmächtigte des NKVD im Frontbereich der Roten Armee, General Serov, anwesend, der für die Sicherung des sowjetisch besetzten Gebietes die entscheidende Rolle spielte ${ }^{149}$. Se-

146 Vgl. Notizen Piecks „Besprechung bei Dimitrov am 30.5. 1945“ und vom 4.6. 1945, ebenda, S. $435 \mathrm{ff}$. und S. $470 \mathrm{f}$. Die auf den 30.5. 1945 datierten Notizen bestehen aus zwei Teilen, die von Keiderling als Vorbereitung Piecks auf das Gespräch und als Protokoll des Gespräches selbst charakterisiert werden (ebenda, S. 440, Anm. 1). Demnach hatte sich Pieck zwar vorgenommen, die organisatorischen Fragen zum Parteiaufbau anzusprechen, was aber am 30. 5. offenbar nicht geschah, sondern erst am 4. 6. 1945. In dem auf den 4.6. 1945 datierten Notat vermerkt Pieck die am 26. 5. 1945 ergangene Anweisung, die Gründung der KPD vorzubereiten, und läßt im Notat den Punkt „Aufbau der KPD“ folgen. Im weiteren Verlauf des Gespräches am 4.6. 1945 ging es dann anscheinend auch um die konkreten Personalfragen („Zusammensetzung der Parteiorgane“); siehe auch Kubina, Der Aufbau des zentralen Parteiapparates, S. 53 ff.

147 Die auf den 4.6. 1945 datierten Notizen Piecks wurden ediert von Badstübner, „Beratungen" bei J. W. Stalin, S. 99 ff.; Keiderling, "Gruppe Ulbricht", S. 468 ff.; Badstübner/Loth, Wilhelm Pieck - Aufzeichnungen zur Deutschlandpolitik, S. 48 ff. und Bodensieck, Wilhelm Piecks Moskauer Aufzeichnungen, S. $28 \mathrm{ff}$. Insbesondere aus der Kritik Bodensiecks, aber auch der von Benser (Quellenveröffentlichungen, S. $101 \mathrm{ff}$.), ist deutlich geworden, daß es sich bei den Notizen nicht um eine Mitschrift eines Gespräches bei Stalin handelt. In der Vergangenheit haben mehrere Autoren in den Pieck-Notizen vom 4.6. 1945 eine unmittelbare Willensäußerung Stalins gesehen: Staritz, Die SED, Stalin und die Gründung der DDR, S. 4 f.; Badstübner, Zum Problem der historischen Alternativen, S. 580 ff.; Raack, Stalin plans his post-war Germany, S. 59 ff.; Loth, Stalins ungeliebtes Kind, S. 21 ff.; zur Diskussion siehe vor allem Loth, Stalin, die deutsche Frage und dic DDR, S. $290 \mathrm{ff}$. und die sich daran anschließende Kontroverse zwischen Loth und Wettig in: DA 28 (1995), S. 743 ff., S. 749 f. und S. 973; siehe auch Wettig, Neue Aufschlüsse über Moskauer Planungen, S. $151 \mathrm{ff}$.

148 Posetiteli kremlevskogo kabineta, S. 103. Das Besucherbuch Stalins vermerkt die Anwesenheit von: Molotov von 17.55 bis 22.00 Uhr und Serov, Ulbricht, Ackermann, Sobottka /fehlerbaft mit "Šapotko" eingetragen] von 18.45 bis $20.30 \mathrm{Uhr}$ sowie als weitere Besucher Chruščev, Antonov, Štemenko, Bulganin, Berija, Malenkov und Mikojan, die aber alle erst nach 20.30 Uhr vorgelassen wurden.

149 "Sicherung" ist in diesem Zusammenhang ein sehr problematischer Begriff, denn das NKVD ging rigoros gegen tatsächlichen und vermeintlichen Widerstand (der Zivilbevölkerung) vor, und war verantwortlich für eine Verhaftungs- und Internierungswelle, die weit über ein sowjetisches Bedürfnis an "Sicherheit" hinausging; zum Vorgehen des NKVD im Frontbereich der Roten Armee siehe Kilian, Stalins Prophylaxe, S. 543 ff.; Semiryaga, Wie 
rov wurde zwei Tage später zum Vize-Chef der SMAD ernannt, der verantwortlich war für die Ziviladministration. Gleichzeitig war er der Geheimdienstkoordinator in der SBZ ${ }^{150}$. Dimitrov und Pieck, die bei diesem Gespräch nicht dabei waren, wurden erst im Anschluß an den Empfang bei Stalin, am späteren Abend des 4. Juni informiert ${ }^{151}$. Die von Pieck auf den 4. Juni 1945 datierten Notizen beziehen sich auf diesen Bericht der Kadergruppenleiter im OMI, über den außerdem das von Laufer veröffentlichte „Stenogramm der Mitteilungen der Genossen Ackermann, Ulbricht und Sobottka über die Lage in Deutschland" vorliegt ${ }^{152}$.

In seinen Notizen über den Bericht im OMI vermerkte Pieck unter dem Absatz „Beschlüsse“ die sofortige Ausarbeitung eines Entwurfs für die Gründung der KPD „bis 5. 6. mittags“. Die Anweisung muß somit in der Nacht vom 4. auf den 5. Juni erfolgt sein. Auch die Anweisung „Liste der Kader für Berlin, Dresden, Rostock; Liste der Kriegsgefangenen vom Nat. Kom. [Nationalkomitee]" muß am 4. Juni erteilt worden sein, denn Serov erhielt am 5. Juni „auf Grund der gestrigen Anweisungen" die entsprechenden Kaderlisten über die Mitglieder des NKFD ${ }^{153}$. Über den Aufruf der KPD und die Kaderlisten war bereits am 30. Mai im OMI gesprochen worden, d.h. die Entwürfe waren vorbereitet und konnten innerhalb von Stunden überarbeitet werden ${ }^{154}$. In Anlehnung an Bodensiecks Edition der Piecknotizen vom 4. Juni, der allerdings als Gesprächspartner nur die KPD-Spitze annimmt, spiegelt das Notat den Entscheidungsablauf getreu wider: Die von eins bis sechs durchnumerierten Absätze halten den Bericht fest, der Stalin vorgetragen und anschließend im OMI wiederholt worden war. Die folgenden Stichpunkte - im Notat ab „Perspektiven“ - beziehen sich auf die Aussprache, in der Dimitrov den deut-

Berijas Leute in Ostdeutschland die Demokratie errichteten, S. $741 \mathrm{ff}$.; allgemein siehe Zeidler, Kriegsende im Osten.

150 Zur Stellung Serovs siehe Foitzik, Sowjetische Militäradministration, S. 161 ff.; Sacharov/ Filippovych/Kubina, Tschekisten in Deutschland, S. $298 \mathrm{ff}$.

151 Pieck vermerkte im Kopf seiner Notizen „Bericht Walter, Ackermann, Sobottka am 4.6. nachm. 8 Uhr" und fügte außerdem hinzu „um 6 Uhr bei Stal., Mol., Shdan.“. Löst man diese Angaben auf, könnten sie bedeuten, daß es um 18.00 Uhr den Bericht bei Stalin, Molotov und Ždanov - der laut Besucherbuch nicht anwesend war - und um 20.00 Uhr die Sitzung im OMI gab; vgl. Bodensieck, Wilhelm Piecks Moskauer Aufzeichnungen, S. 39. Die Bezeichnung „nachmittags“ halte ich für einen Russizismus, der - abgeleitet von „posle obeda/nach dem Mittagessen“" (so wie im Englischen „p.m.") - anzeigt, daß es sich nicht um 8.00 Uhr früh, sondern um 20.00 Uhr abends handelte.

152 Laufer, „Genossen, wie ist das Gesamtbild?“, S. $355 \mathrm{ff}$. Laufer datiert das Stenogramm des OMI auf den 7.6. 1945, aber meines Erachtens protokolliert es genau das Gespräch, von dem auch Pieck Notizen angefertigt hat. Inhaltlich passen Notizen und Stenogramm zusammen, wobei das Stenogramm nur den Bericht, aber nicht die Diskussion festhielt. Die Erklärung dafür könnte darin bestehen, daß das OMI nach dem nicht protokollierten Gespräch bei Stalin den Bericht über die Situation in Deutschland schriftlich fixieren sollte, während die daran anschließende Diskussion und die „Beschlüsse“ nicht in das Stenogramm aufgenommen wurden, weil es über das OMI hinaus verbreitet wurde. Laufer datiert das Stenogramm auf den Zeitpunkt der Erstellung der Klarschrift am 7.6. 1945. An diesem Tag gab es ein zweites Gespräch bei Stalin, für das das Stenogramm möglicherweise die Gesprächsgrundlage bot.

153 Pieck an Serov am 5. 6. 1945, SAPMO-BArch 4036/517, Bl. 145-146; unvollständige Wiedergabe in: "Gruppe Ulbricht", S. 475; vgl. ebenda, S. 471 die Notizen Piecks vom 4. 6. 1945.

154 Notizen Piecks „Besprechung bei Dimitrov am 30. 5. 1945“, ebenda, S. 435 ff.; vgl. Keiderlings Kommentar ebenda, S. 472 f., Anm. 1. 
schen Kommunisten den sowjetischen Standpunkt erläuterte, und die mit den Anweisungen Dimitrovs an die KPD - im Notat als „Beschlüsse“ gekennzeichnet endete ${ }^{155}$.

Im Mittelpunkt des Berichtes an das OMI, den in der Hauptsache Ackermann vortrug, standen die allgemeine Haltung der Bevölkerung, die Meinungen der NSGegner, die aus dem Untergrund auftauchten oder aus Konzentrationslagern und Gefängnissen befreit worden waren, das Auftreten von Sozialdemokraten, die Versorgungs- und Verkehrslage und nicht zuletzt die Situation in den Besatzungszonen der Westalliierten ${ }^{156}$. Bei der Schilderung über den Aufbau der Kommunalverwaltungen („Selbstverwaltungen“) ging Ackermann auf alle vom OMI im März 1945 benannten Aufgaben ein: Ernennung von Bürgermeistern und Besetzung der Verwaltungsstellen, Sicherung der kommunalen Wirtschaft (Strom, Wasser), Räumung der Straßen und Versorgung der Bevölkerung ${ }^{157}$. Auch Ulbricht, der in seinem Vortrag allerdings den Aufbau einer Parteiorganisation stärker in den Vordergrund stellte und damit den anstehenden Entscheidungen offenbar vorgreifen wollte, ging ebenfalls ausführlich auf die "Selbstverwaltungen“ ein. Er schilderte das Problem, daß örtliche Initiativen bereits die Aufgaben übernommen hätten, die den aus Moskau angereisten Kadern aufgetragen worden seien. Um eine „Doppelherrschaft“ $z u$ vermeiden, seien die Komitees aufgelöst worden. Ulbricht kleidete das in die für sein Denken bezeichnende Worte, mit denen er seinen Vortrag begann: „Als unsere Gruppe nach Berlin kam, wurde in einigen Stadtteilen noch gekämpft. In anderen Stadtteilen herrschte bereits unsere Macht." 158

Die Sorge um die politische Kontrolle der Roten Armee war das zentrale Anliegen des OMI. Die während des Vortrags gestellten Nachfragen bezogen sich auf das Verhalten der Jugendlichen, insbesondere auf befürchtete Partisanenaktionen des "Werwolf“, und auf politische Aufrufe, die möglicherweise aus dem Westen hätten kommen können. In diesem Zusammenhang erkundigte sich das OMI vor allem nach dem Verhalten von Thomas Mann ${ }^{159}$. Zudem interessierte sich das OMI für das Verhalten der Kriegsgefangenen, die der 7. Verwaltung zur Unterstützung geschickt worden waren. Auch bei diesen Kadern dominierte die Sorge, man könne die Kontrolle verlieren. Ackermanns rundum positive Beurteilung der organisatorischen Arbeit der Kriegsgefangenen wurde mit der Bemerkung unterbrochen, „Die Rede ist vom politischen Benehmen“. Ulbricht nannte daraufhin den erfolgreichen

155 Bodensieck, Wilhelm Piecks Moskauer Aufzeichnungen, S. 38.

156 Laufer, "Genossen, wie ist das Gesamtbild?", S. $358 \mathrm{ff}$.

157 Ebenda, S. 360 f.; vgl. Dimitrov und Panjuškin an Molotov und Malenkov im März 1945, in: Sowjetische Politik in der SBZ, S. $5 \mathrm{f}$.

158 Laufer, „Genossen, wie ist das Gesamtbild?", S. $364 \mathrm{f}$.

159 Thomas Mann war nach der Gründung des NKFD von einem sowjetischen Korrespondenten in den USA zu einer Stellungnahme gedrängt worden. Seine Haltung schwankte jedoch, da er der moskautreuen Haltung des Nationalkomitee mißtraute. Die von kommunistischer Seite schließlich stolz präsentierte Zustimung Manns zum NKFD (Weinert, Nationalkomitec, S. 104) war lediglich „auf Bitten der sowjetischen Nachrichtenagentur TASS eine verhalten zustimmende Erklärung zur Bildung des NKFD“ (Bungert, Deutsche Emigranten im amerikanischen Kalkül, S. 264). Thomas Mann wurde im Herbst 1943 in den USA mehrmals gefragt, ob er bercit sei, in einem "Gegenkomitee" mitzuwirken, was er jedoch ablehnte. Da der sowjetische Geheimdienst darüber vermutlich Kenntnis hatte, ist die Nachfrage des OMI im Juni 1945 verständlich. 
Einsatz eines „Jugendinstrukteurs“, der Antifa-Schüler sei (vermutlich Heinz Keßler) ${ }^{160}$. Offenbar ging die vom OMI den Kriegsgefangenen zugedachte Funktion nicht über die rein pragmatische Hilfe beim Aufbau der Kommunalverwaltungen hinaus. Antifa-Kader sollten den Kontakt zur deutschen Bevölkerung herstellen, deren innere Einstellung der sowjetischen Besatzungsmacht fremd, wenn nicht sogar ein wenig unheimlich war, und damit für eine gesellschaftliche Kontrolle - im konkreten die Angst vor jugendlichen Werwölfen - sorgen.

Am Abend des 4. Juni wurde im OMI außerdem über die weitere Entwicklung des von alliierten Truppen besetzten Deutschland gesprochen. Der von Pieck notierte Satz „Perspektive - es wird 2 Deutschlands geben - trotz allem Einheit der Verbündeten " 161 bedeutete in diesem Zusammenhang lediglich, daß es in Deutschland eine östliche und eine westliche Besatzungszone, aber trotz der eigenständigen Militärverwaltungen in den Zonen durch den alliierten Kontrollrat eine einheitliche Kontrolle über Deutschland geben werde. In eben dieser Weise erläuterte Pieck den KPD-Mitgliedern in Moskau am 27. Juni 1945 die Situation: „Entwicklung der Lage in zwei Monaten seit dem 2.5. 1945. Teilung in zwei Besatzungszonen, sowjet- und alliierte, östliche und westliche (...) Perspektiven - demokratische Erneuerung: kämpferische Demokratie - Aufbau - wirtschaftliche, geistige und moralische Gesundung der Völker - nationale Selbständigkeit. Freies Deutschland - Nationalkomitee."162 Auch wenn die sowjetische Führung damit ein Zusammengehen der Westalliierten als gegeben voraussetzte - die westlichen Zonen wurden zusammengefaßt zu einer "alliierten Zone“ -, so sollte die Entwicklung in der sowjetischen Zone jedoch nicht anders verlaufen. In der Diskussion mit den KPDFunktionären am Abend des 4. Juni stellte Dimtrov klar, daß ebenso wie in den westlichen Zonen auch in der SBZ zuerst die Verwaltungen in Ordnung gebracht würden. Auf Orts- und Kreisebene war das bereits begonnen worden, aber nun sollte auch die Etablierung von Landesverwaltungen in Angriff genommen werden. Eine zonenübergreifende, gesamtdeutsche Verwaltung war damit allerdings nicht vorgesehen. Pieck notierte: „Administrative Regelung: Engländer - Amerikaner schaffen Regierungen für Bayern, Thüringen, Rheinlandpfalz-Rheinland. Wir Landesregierung für Sachsen, Provinzialregierungen für Berlin-Brandenburg, Mecklenburg-Pommern; ob später fürs ganze Okkupationsgebiet ist noch nicht klar. Schaffung von Verwaltungen für Bezirk, Kreis, Stadt, Gemeinde."163

Am 4. Juni wurde zudem die Tätigkeit politischer Parteien in den gesellschaftlichen Aufbau in der SBZ einbezogen. Vor dem Einsatz deutscher Kader war davon noch nicht die Rede gewesen. Nach dem erfolgten Einsatz wurde diese Frage schon nicht mehr diskutiert, denn die Zulassung von Parteien stand bereits fest. In Piecks Aufzeichnungen heißt es kommentarlos, daß außer den Verwaltungen und den Par-

160 Laufer, „Genossen, wie ist das Gesamtbild?", S. 371.

161 Siehe Bodensieck (Wilhelm Piecks Moskauer Aufzeichnungen, S. 37), der überzeugend darlegt, daß es im Original "trotz allem Einheit der Verbündeten" heißt und nicht wie in den meisten Arbeiten, die aus der Klarschrift zitieren, „trotz aller“. Die Konnotation ist daher: "Die Alliierten gehen gemeinsam vor, obwohl es zwei Zonen gibt".

162 "Information der Parteimitglieder in Moskau im Lux" am 27.6. 1945, in: „Gruppe Ulbricht", S. $589 \mathrm{f}$.

163 Zitiert nach der Edition von Bodensieck, Wilhelm Piecks Moskauer Aufzcichnungen, S. 52; dort gekennzeichnet als „[A II: 2]“ und „[A II: 3]“. 
teien keine weiteren Korporationen wie Antifa-Komitees oder Verbände zugelassen werden sollten: „Schaffung besonderer Bauernbund nicht zweckmäßig, sondern innerhalb der Partei einbeziehen. Bildung antifaschistischer Komitees auch nicht zweckmäßig - weil Gefahr, daß neben Stadt und Gemeindeverwaltung eigenmächtig."164 Ebenso übergangslos hieß es nun „alte Schulbücher benutzen, von Weimar und Österreich" "165, obwohl sich das Institut 99 mit viel Aufwand um die Umgestaltung des Bildungswesens gekümmert hatte. Planungen und Vorarbeiten wurden beiseite geschoben. Es ging dem OMI - vorerst - um eine Anknüpfung an die gesellschaftlichen Verhältnisse in Deutschland vor der nationalsozialistischen Machtergreifung. Allerdings gab es eine wesentliche Ausnahme: Die ländlichen Besitzverhältnisse sollten durch eine Bodenreform radikal verändert werden ${ }^{166}$. Über die Grundzüge der sowjetischen Politik in der SBZ im Sommer 1945 notierte Pieck:„Charakter des antifaschistischen Kampfes: Vollendung der bürgerlichdemokratischen Revolution - bürgerlich-demokratische Regierung - Macht der Rittergutsbesitzer brechen - Rest des Feudalismus beseitigen." 167

Das von Pieck auf den 4. Juni 1945 datierte Notat hält die Diskussion Dimitrovs - sowie weiterer Personen, von denen nur Panjuškin (stellvertretender Chef des OMI) im Protokoll namentlich erwähnt wird - mit der KPD-Spitze und nicht ein Gespräch mit Stalin fest. Es entsprach dabei den sowjetischen Gepflogenheiten, daß auf der ZK-Ebene - dem OMI - die inhaltlichen Diskussionen geführt wurden, während der politischen Spitze - Stalin - nur knapp berichtet wurde. Dessen $\mathrm{Zu}$ stimmung oder Ablehnung entschied jedoch über den weiteren Gang der Dinge. Die zweite, am 7. Juni folgende Besprechung bei Stalin war somit die unbedingt notwendige Bestätigung der in der Zwischenzeit erarbeiteten Vorlagen. Bis zu dieser zweiten Besprechung wurden die am 4. Juni verabschiedeten „Beschlüsse“ abgearbeitet. Es gab tägliche Beratungen im OMI 168 .

Parallel zu den konzeptionellen Arbeiten im OMI wurden in den Tagen zwischen dem 4. und 7. Juni die maßgeblichen Beschlüsse zur Errichtung der Sowjetischen Militäradministration in Deutschland (SMAD) verabschiedet. Der ursprünglich vorgesehene Termin (1. Juni) ${ }^{169}$ war nicht zu halten gewesen, vermutlich weil der alliierte Beschluß über die Übernahme der Regierungsgewalt in Deutschland erst am 5. Juni fiel. Am 6. Juni entschied der Rat der Volkskommissare über die sowjeti-

164 Ebenda; als „, [A II: 6]“ und „[A II: 7]“ gekennzeichnet.

165 „[A II: 4] Schulfragen - Entwurf [damit war offensichtlich der Richtlinienentwurf der NKFD-Kommission gemeint: Alte Lehrbücher benutzen von Weimar und Österreich“, ebenda. Einzige Einschränkung war der Religionsunterricht, der nur noch außerhalb der Schule zugelassen werden sollte, ebenda „[A II: 5]“.

166 In der Rückschau kann zu diesem Punkt ergänzt werden, daß es der Sowjetunion beim deutschen Einigungsvertrag von 1990 besonders wichtig war, die Bodenreform in der SBZ nicht rückgängig zu machen. Bis auf die Enteignungen durch die Bodenreform wurden alle anderen Besitzverhältnisse in der ehemaligen DDR getreu des Grundsatzes „Rückgabe vor Entschädigung" revidiert.

167 Bodensieck, Wilhelm Piecks Moskauer Aufzeichnungen, S. 52, „[A II: 1]“. Dieser Punkt wurde in der Diskussion im OMI zuerst angesprochen und kann daher als eine Art Eingangsvoraussetzung für alle folgenden Punkte, auf die Dimitrov im weiteren zu sprechen $\mathrm{kam}$, betrachtet werden.

168 Vgl. den von Benser (Quellenveröffentlichungen, S. 102) ziticrten Kalender Piecks.

169 Creuzberger, Die sowjetische Besatzungsmacht, S. 27. 
sche Militäradministration. Diese Entscheidung wurde als SMAD Befehl Nr. 1 am 9. Juni veröffentlicht, gefolgt vom Befehl Nr. 2 vom 10. Juni über die Zulassung antifaschistischer Parteien in der SBZ ${ }^{170}$. Rein vom chronologischen Ablauf her fügte sich die Berichterstattung deutscher Kommunisten bei Stalin und im OMI nahtlos in den Aufbau der sowjetischen Militärverwaltung in Deutschland. Mit den deutschen Kommunisten sind diese Erlasse aber nicht diskutiert worden, auch wenn ganz offensichtlich vom OMI Wert auf die Berichterstattung gelegt wurde. Es ist dabei nicht auszuschließen, daß sich das OMI neben der Politischen Hauptverwaltung der Roten Armee und dem Volkskommissariat für Äußere Angelegenheiten, das seinerseits politische Berater nach Deutschland geschickt hatte, eine eigene Informationsbasis sichern wollte ${ }^{171}$.

Am 7. Juni sprachen Ulbricht, Ackermann und Sobottka abermals bei Stalin vor, nun zusammen mit Pieck und Dimitrov. Im Unterschied zu der kurzen Sitzung drei Tage zuvor tagte man dieses Mal fast vier Stunden lang („21.35 - 1.30 Uhr“"172. Obwohl die verhandelten Beschlußvorlagen in den vergangenen Tagen in enger Absprache mit Dimitrov erarbeitet worden waren, bestand immer noch großer Klärungsbedarf. Vor allem in der Frage der Neugründung der KPD sowie des Parteiensystems insgesamt gab es ganz offensichtlich Meinungsverschiedenheiten. Dimitrov notierte in sein Tagebuch: „Treffen bei Stalin (und Molotov). Berieten den Entwurf der deutschen KP. Es wurden wesentliche Änderungen vorgenommen. (...). Stalin schlug vor, definitiv zu erklären, daß im gegebenen Moment die Einführung des sowjetischen Systems in Deutschland unrichtig ist; notwendig ist die Errichtung eines antifaschistischen, demokratischen, parlamentarischen Regimes. Die kommunistische Partei schlägt einen Block antifaschistischer Parteien auf einer gemeinsamen Plattform vor." 173 Die erneute Überarbeitung der vom OMI und der KPD gemeinsam formulierten Vorlagen läßt darauf schließen, daß die sowjetische Führung in ihrer Haltung zu Einzelfragen wie dem Parteiensystem und der Stellung der KPD schwankend war. Hatte bis zur Einstellung der Kampfhandlungen und

170 Ebenda, S. 29 ff.; Foitzik, Sowjetische Militäradministration, S. 84 und $97 \mathrm{ff}$.

171 Foitzik (Sowjetische Militäradministration, S. $334 \mathrm{f}$.) verweist zu recht auf die vollkommen unabhängig von den deutschen Kommunisten errichteten Verwaltungsstrukturen der SMAD, unterschätzt aber die oben dargestellte Koinzidenz der Entscheidungsabläufe in Moskau. Die später fortwährenden Konflikte zwischen Außenministerium und Zentralkomitee bei der Bewertung - und Beeinflussung - der politischen Entwicklung in der SBZ basierte meines Erachtens auf eben diesen parallelen Strukturen, die sowohl die Wahrnehmung in Moskau als auch die daraus resultierenden Entscheidungen beeinflußten. In der Forschung sind Form und Stellenwert der jeweiligen Kommunikationswege der SMAD über die Informationabteilung (Tjul'panov) oder den politischen Berater des Außenministeriums (Semenov) umstritten. Foitzik schreibt Semenov den maßgeblichen Einfluß zu (S. 247) und betont, daß die SED auch über direkte Verbindungswege in den Moskauer ZKApparat verfügte (S. 261); demgegenüber siehe Naimark, Russen in Deutschland, S. $403 \mathrm{ff}$. Als nicht haltbar hat sich Loths Interpretation (Stalins ungeliebtes Kind, S. 129ff.) erwiesen, wonach die sowjetische Deutschlandpolitik entgegen der Intention Stalins von Ulbricht und Tjul'panov ausgestaltet worden sei. Siehe auch die umfangreichen Dokumentationen $\mathrm{zu}$ den Berichten des Außenministeriums (SSSR i germanskij vopros, tom II) und der Propagandaverwaltung der SMAD (Sowjetische Politik in der SBZ).

172 Posetiteli kremlevskogo kabineta, S. 103.

173 Eintrag in Dimitrovs Tagebuch vom 7. 6. 1945; zitiert nach Wolkow, Die deutsche Frage aus Stalins Sicht, S. 26. 
dem anschließenden Aufbau einer Militärverwaltung das Gesetz des Handelns gegolten, so ging es nun um zukunftsweisende Strukturentscheidungen, mit denen sich die Sowjetunion festlegen mußte. Der Bericht bei Stalin war dabei eine wichtige Zäsur für die sowjetische Deutschlandpolitik wie auch für die weiteren Kadereinsätze. Er war vom OMI von Anfang an eingeplant worden. Mitte Februar hatte Panjuškin den Ablaufplan entworfen, daß in der „1. Phase“ lediglich Hilfestellung für den Aufbau einer sowjetischen Besatzungsverwaltung in Deutschland geleistet werden, dann Bericht in Moskau erstattet und schließlich eine „2. Phase“ mit „erweiterten Aufgaben" folgen solle ${ }^{174}$. Die laut Stenogramm des OMI vom 4. Juni von Ackermann in seinem Vortrag gebrauchten rhetorischen Fragen („Genossen, wie ist das Gesamtbild?") verdeutlichen, daß es dem OMI - wie auch vermutlich Stalin - am 4. Juni vorerst nur um ein Stimmungsbild ging, um daraufhin in der am 7. Juni folgenden Sitzung Entscheidungen für die „2. Phase“ treffen zu können. Ganz offensichtlich war sich die sowjetische Führung vor dem Bericht Ackermans, Sobottkas und Ulbrichts noch gar nicht im konkreten klar darüber, was in der "2. Phase" in der SBZ geschehen sollte. Die Festlegung erfolgte tatsächlich erst am 7. Juni. Im Anschluß an die Sitzung bei Stalin überarbeitete die KPD abermals ihre Vorlagen zur Neugründung der KPD in Deutschland ${ }^{175}$. Pieck übersandte dieses Material am 9. Juni an Dimitrov, der es am 11. Juni an Stalin weiterleitete ${ }^{176}$. Am 12. Juni wurde der Gründungsaufruf der KPD veröffentlicht.

Nach der Berichterstattung in Moskau wurde eine fünfte Kadergruppe nach Deutschland geschickt. In der Mehrzahl setzte sie sich aus Politemigranten zusammen (59 Kommunisten, 20 Kriegsgefangene), deren Zahl nach dem zweiten Treffen mit Stalin von 31 auf 59 nahezu verdoppelt worden war. In der Hauptsache waren für die fünfte Gruppe kommunistische Intellektuelle ausgewählt worden, die sich zum Teil in der sogenannten Kulturkommission der KPD mit den Fragen der Entnazifierung auseinandergesetzt hatten (Becher, Plivier, Bredel, Wangenheim, Vallentin, Wolf). Allerdings rückte durch die nach dem 7. Juni eingereichte „Ergänzungsliste“ der Aufbau des Parteiapparates der KPD stärker in den Vordergrund. Nachträglich wurden 28 Parteifunktionäre für die Bezirke Berlin, Halle-Merseburg, Thüringen und Pommern benannt ${ }^{177}$. Diese zusätzlich nominierten Kommunisten waren ursprünglich vorgesehen für den Monatskurs, der jedoch nicht zustande gekommen war. Wegen des akuten Personalmangels wurde daher bei der Nominie-

174 Vgl. Notizen Piecks über die Besprechung bei Panjuškin am 17. 2. 1945, in: „Gruppe Ulbricht", S. 206.

175 Ebenda, S. $509 \mathrm{ff} .:$ „Nächste zentrale Aufgaben der Parteiführung aufgrund des Aufrufes des ZK der KPD“, „Grundlage für den Etat des ZK der KPD“, „Grundlage für einen Etat der Parteizeitungen". Inhaltlich wurden alle diese Beschlüsse bereits in den Notizen Piecks vom 4. 6. 1945 erwähnt.

176 Pieck an Dimitrov am 9. 6. 1945, SAPMO-BArch NY 4036/544, Bl. 204; Dimitrov an Stalin am 11.6. 1945 (inklusive Anlagen), RGASPI 17/128/716, Bl. 63-72; Die Anlagen waren außer der „Ergänzungsliste“: „Ubersicht über die Verteilung der im Mai [und im Juni] 1945 zum Einsatz gelangten Genossen auf die einzelnen Gebiete“, ebenda, Bl. 152-154; „Übersicht über die bei den einzelnen Institutionen in Moskau verbleibenden Genossen“, ebenda, Bl. 155-156. In „Gruppe Ulbricht“, S. 507f. (Ergänzungsliste), S. 441 f. und 506 f. (Liste eingesetzter Kader), sind diese Dokumente nur unvollständig wiedergegeben.

177 „Ergänzungsliste zur Liste vom 5. 6. 1945“, ohne Datum, SAPMO-BArch NY 4036/517, Bl. 147-150; siehe Anlage Nr. 3. 
rung weiterer Kader auf eine vorangegangene Parteischulung verzichtet. Sie wurde allerdings noch vor Abreise der Gruppe nachgeholt. Die Nominierung der Politemigranten entsprach somit - zumindest quantitativ - genau dem von Ulbricht gegenüber dem OMI angemeldeten Bedarf. Von einer Verwendung von Kriegsgefangenen für den Aufbau des KPD-Apparates in Deutschland hatte er abgeraten: „Was die weitere Verwendung der Kriegsgefangenen anbelangt, so ist die Lage folgende. Jetzt brauchen wir Leute, die eine mehr oder minder hohe politische Ausbildung haben. Was die übrigen Genossen betrifft, so werden etwa 50 Mann für die Arbeit gebraucht." 178

Mit der fünften Gruppe kehrten aber auch Kriegsgefangene nach Deutschland zurück. Sie waren vorgesehen für die Gebiete Sachsen, Berlin-Brandenburg und Mecklenburg-Pommern, den Einsatzgebieten der ersten vier Gruppen. Ausgewählt wurden Aktivisten des Nationalkomitees, deren loyale Haltung zur Sowjetunion als erwiesen galt. Nur die wenigsten von ihnen hatten die Antifa-Schule besucht. Als Qualifikation galt bei der Kaderbeurteilung die Mitarbeit in den Redaktionen des NKFD ebenso wie die Tätigkeit als Lager- oder Frontbevollmächtigter ${ }^{179}$. Die den Kadern zugedachte gesellschaftspolitische Funktion ist aus den Kaderbeurteilungen zu ersehen. Zu dem katholischen Oberst Steidle hieß es: „Er könnte bei der Arbeit in Deutschland ein wichtiges Bindeglied zwischen den katholischen Volksgruppen und den Arbeiterparteien darstellen." Über den evangelischen Wehrmachtspfarrer Schröder wurde geurteilt, daß er sich „in seinen Predigten und Reden mehr von den Interessen des antifaschistischen Kampfes als von denen der evangelischen Kirchen leiten" lasse. Und die Kaderbeurteilung über den Truppenarzt Dr. Rudi Pallas lautete: „In Anbetracht seiner Herkunft aus der bürgerlichen Jugendbewegung dürfte er bei seiner Arbeit in Deutschland als Bindeglied zwischen der bürgerlichen und der Arbeiterjugend eine erhebliche Rolle spielen." 180 Ursprünglich hatte die Zusammenstellung der fünften Kadergruppe das Ziel gehabt, den Aufbau antifaschistischer Massenorganisationen, insbesondere des Kulturbundes, sowie den Aufbau neuer Landesverwaltungen zu unterstützen. Erst durch die „Ergänzungsliste" wurden Parteifunktionäre im engeren Sinne zum Aufbau des Parteiapparates hinzugenommen. Auch das ist ein Indiz für den Stellenwert der Berichterstattung Ackermanns, Ulbrichts und Sobottkas bei Stalin bzw. im OMI.

Zusammenstellung und Einsatz der fünften Gruppe bedeuteten das Ende der Parteischulung der KPD in der Sowjetunion. Die Rückreise der Gruppe zog sich bis zum Jahresende 1945 hin. Diejenigen kommunistischen Intellektuellen, deren Ein-

178 Laufer, „Genossen, wie ist das Gesamtbild?“, S. 371.

179 Pieck an Serov am 5. 6. 1945, SAPMO-BArch 4036/517, Bl. 145-146; unvollständige Wiedergabe in: „Gruppe Ulbricht“, S. 475. Als „ergebene“, „zuverlässige“ oder „bewährte Antifaschisten" wurden vorgeschlagen: Rücker, Kohlmay, von Kügelgen, Emendörfer, Krummacher, Krausnick (für den Einsatz in Berlin), Hadermann, Kertzscher, Röckl, Gerhard Krüger, Reyher, Klement, Achilles (für den Einsatz in Sachsen) und Grandy, Hartmann, Dengler, Strampfer, Helmschrott, Luddeneit, Gentzen (für den Einsatz in Mecklenburg). Ein weiteres Auswahlkriterium wird der Wohnort gewesen sein, bzw. die Bereitschaft der eingesetzten Kriegsgefangenen, sich von der Familie zu trennen, sofern sie nicht dazu bewegt werden konnte, in die SBZ überzusiedeln; vgl. Steidle, Entscheidung an der Wolga, S. 399.

180 Von Weinert am 15.9. 1945 ausgestellte Charakteristiken, RGASPI 17/128/839, Bl. 126-129. 
satz am 5. Juni beschlossen worden war, fuhren Mitte Juni nach Deutschland ${ }^{181}$. Diejenigen aber, die in der „Ergänzungsliste“ zusätzlich nominiert worden waren, wurden vor der Abreise zusammen mit den ausgewählten Aktivisten des NKFD politisch geschult. Nach den Erinnerungen der Beteiligten kamen sie in der Schule Nr. 12 in Schodna zusammen ${ }^{182}$. Aber offenbar wurde die Gruppe unter der Bezeichnung "Schule der $30^{\circ}$ in dem Ausbildungscamp Nagornoe als eigenständige Schulungsgruppe, d. h. nicht als Kurs an der Parteischule, ausgebildet ${ }^{183}$. Ihre Rückreise erfolgte im November 1945, nach Auflösung des Nationalkomitees ${ }^{184}$. Ungeachtet dessen führte die Schule Nr. 12 von Oktober bis November 1945 noch den vierten und letzten Kurs durch. Die vom Institut 99 organisierte Parteischulung der KPD in der Sowjetunion brachte somit insgesamt 210 ausgebildete Emigranten und Kriegsgefangene hervor. Von ihnen wurden 121 Kader (ca. 90 von ihnen waren Kriegsgefangene) in der Schule Nr. 12 vorbereitet. In der Abendschule wurden 89 Mitglieder der Exil-KPD geschult. Nachweislich kehrten in der Zeit von April bis Dezember 1945 insgesamt 249 Kader in fünf Gruppen zurück: 139 Kriegsgefangene und 110 Politemigranten. Von den Kriegsgefangenen hatten 33 die Schule Nr. 12 beendet, 15 zählten zu den Aktivisten des NKFD. Von den Emigranten absolvierten acht die Schule Nr. 12 und 23 die Abendschule. Demnach hätten lediglich 64 der unmittelbar nach Kriegsende in Deutschland eingesetzten Kader die dafür vorgesehenen Parteischulungen besucht ${ }^{185}$. D. h. zusätzlich zu den fünf Kadergruppen waren ca. weitere 150 Kommunisten für den Einsatz in Deutschland ausgebildet, aber nicht sofort eingesetzt worden. Möglicherweise sind sie erst nach dem Jahresende 1945 eingesetzt worden. Laut Erler sind bis Ende 1945 nachweisbar 116 Politemigranten nach Deutschland zurückgekehrt. Weitere 102 folgten in den Jahren 1946 und $1947^{186}$.

Erler bezeichnet die in den Jahren 1945-1947 aus der Sowjetunion zurückkehrenden kommunistischen Emigranten als "Moskau-Kader“, die im Parteiapparat der $\mathrm{KPD} / \mathrm{SED}$ und in der staatlichen Verwaltung der SBZ/DDR die entscheidenden Führungspositionen übernahmen. Als Gruppe seien sie durch folgende „Integrations- und Identifikationsfaktoren“ zusammengehalten worden: „Erlebnisse und Erfahrungen im gemeinsamen Emigrationsland, die dort erhaltene Ausbildung, die politisch-emotionale Bindung an die Sowjetunion, die prinzipielle Bejahung des sowjetischen Gesellschaftsmodells auch für Deutschland und der widerspruchslose Gehorsam gegenüber sowjetischen Funktionären." 187 Dabei ist allerdings zu berücksichtigen, daß der Aufbau des Parteiapparates und die Besetzung der Schlüsselpositionen mit „Moskau-Kadern“ mitnichten so stringent war, wie es in der Rückschau scheinen mag. Bereits die Absolventen des dritten Kurses an der Schule Nr. 12 (Mai 1945) waren bei der Kaderauswahl im Juni 1945 nicht berücksichtigt

181 Erler, „Moskau-Kader“, S. 252.

182 Dengler, Zwei Leben in einem, S. 131 ff.; Kügelgen, Nacht der Entscheidung, S. 473 f.; vgl. Puttkamer, Irrtum und Schuld, S. 87; Steidle, Entscheidung an der Wolga, S. 396 f.

183 Erler, „Moskau-Kader“, S. 251. Erler täuscht sich, wenn er die „Schule der 30“ mit dem gescheiterten „Monatskurs“ gleichsetzt.

184 Ebenda, S. 252.

185 Siehe Anlage Nr. 3.

186 Erler, Moskau-Kader, S. 253 u. 255.

187 Ebenda, S. 231. 
worden, weil offensichtlich in Deutschland mehr organisationserfahrene Parteifunktionäre angetroffen worden waren als angenommen. Zumindest hatte der aus Berlin zurückgekehrte Ulbricht gegenüber dem OMI auf die ausreichend vorhandenen Funktionäre hingewiesen: „Überhaupt, an Kadern ist kein Mangel, sogar leitende Kader sind ausreichend vorhanden. Die Bezirksleitungen bestehen alle aus ehemaligen Funktionären der Kommunistischen Partei Deutschlands und aus einer ganzen Reihe ehemaliger Reichstagsabgeordneter, die jetzt mitarbeiten. Großer Bedarf besteht an Leuten, die ideologisch beschlagen sind."188 Die für die fünfte Gruppe zusätzlich nominierten Parteifunktionäre wurden offenbar als besonders qualifiziert von der KPD-Führung angefordert, dafür spricht auch ihre von der regulären Parteischulung abgesonderte Vorbereitung. Gleichzeitig war damit der Bedarf an Parteifunktionären gedeckt. Die mit der fünften Gruppe nach Deutschland zurückkehrenden Kader reichten für den Apparat der KPD in Deutschland offensichtlich vollkommen aus. Auch Erler konstatiert, daß etliche „MoskauKader" erst im Zuge der gesellschaftlichen Veränderungen in der SBZ in entsprechende Schlüsselpositionen aufrückten. Einzige Ausnahme war die Besetzung des Zentralkomitees der KPD bzw. des Zentralsekretariat der SED, in dem von Anfang an fast nur „Moskau-Kader" vertreten waren 189 .

Die in der Sowjetunion auf den Einsatz in Deutschland vorbereiteten Kader Kriegsgefangene wie kommunistische Emigranten - dienten nicht bevorzugt dem Aufbau des Parteiapparates der KPD in Deutschland. Ihre Verwendung stand unter Leitung der Propagandaverwaltung der SMAD, die aus den 7. Verwaltungen der Fronten hervorgegangen war, und deren Mitarbeiter auf einschlägige Erfahrungen in der Zusammenarbeit mit Antifa-Schülern in der Frontpropaganda zurückgreifen konnten ${ }^{190}$. Insbesondere der Leiter der Propagandaverwaltung, Oberst Tjul'panov, hatte während seiner Tätigkeit als Chef einer 7. Verwaltung an der Front frühzeitig auf das Potential der geschulten Kriegsgefangenen für den Aufbau der Verwaltungen in dem besetzten Gebiet hingewiesen ${ }^{191}$. Analog zu den vom OMI im März 1945 formulierten Aufgaben der Kadergruppen berichtete auch die politische Hauptverwaltung Anfang Juli: „Gemäß den Direktiven der Stavka [Oberkommando der Roten Armee] ist von den Politorganen eine intensive Arbeit zur Schaffung von Organen der lokalen Selbstverwaltung (Magistrate in den Städten, Bürgermeistern in den Dörfern), der Polizei und des Gerichtswesens sowie der Auswahl entsprechender antifaschistischer Kader aus der örtlichen Bevölkerung durchgeführt worden. (...) Zur Ausfindigmachung und Auswahl der Kader der Oberbürgermeister, Bürgermeister, deren Stellvertreter, der Leiter der Magistratsabteilungen, der Bürgermeister in den Landgemeinden und anderer Mitarbeiter der lokalen deutschen Verwaltung sind Hunderte von Gesprächen mit der örtlichen Bevölkerung durchgeführt worden. Das hat es ermöglicht, Antifaschisten zu finden und zur Arbeit heranzuziehen. Viele der Bürgermeister und ihrer Stellvertreter und

188 Laufer, „Genossen, wie ist das Gesamtbild?“, S. 371.

189 Erler, „Moskau-Kader“, S. 277 ff.

190 Zur Propagandaverwaltung der SMAD siehe Naimark, Russen in Deutschland, S. $26 \mathrm{ff}$;; Bonwetsch in der Einleitung von: Sowjetische Politik in der SBZ, S. XXVII ff.

191 Vgl. Tjul'panovs Äußerungen auf dem zweiten Armeetreffen im Mai 1944; siehe oben S. 115 . 
Räte sind ehemalige Mitglieder der KPD."192 Im Sommer 1945 wurden sogar mehr Kader unmittelbar über die Fronten der Roten Armee als zentral über das Institut 99 bzw. das OMI in Moskau eingesetzt. Das GlavPURKKA berichtet im Juli über den Einsatz von 300 Kriegsgefangenen und 70 kommunistischen Emigranten ${ }^{193}$. Zu diesem Zeitpunkt aber waren erst vier Gruppen aus Moskau geschickt worden (52 Kommunisten und 119 Kriegsgefangene), und lediglich ein Teil der fünften Gruppe (nominiert waren 31 kommunistische Intellektuelle) auf dem Weg nach Deutschland. Demnach wurden ca. zwei Drittel aller unmittelbar nach Kriegsende in Deutschland als Kader eingesetzten Kriegsgefangenen über die antifaschistischen Frontschulen der 7. Verwaltung und nicht über das Institut 99 rekrutiert. Sie halfen der SMAD beim Aufbau der Verwaltung in der SBZ.

192 „Auskunft der Politischen Hauptverwaltung der Streitkräfte der UdSSR über die politische Arbeit unter der Bevölkerung Deutschlands" vom 5. 7. 1945, in: Sowjetische Politik in der SBZ, S. 9.

193 Ebenda, S. 8. 